Supporting information for

\title{
Nitric Oxide Prodrug Delivery and Release Monitoring Based on Galactose-Modified Multifunctional Nanoprobe
}

Yijing Dang, ${ }^{\dagger}$ Liting Ruan, ${ }^{\dagger}$ Yang Tian,${ }^{\dagger}$ Zhiai Xu $,{ }^{\dagger}, *$ Wen Zhang ${ }^{\ddagger} *$

$\dagger$ School of Chemistry and Molecular Engineering, East China Normal University, Shanghai 200241, China

¥Shanghai Engineering Research Center of Molecular Therapeutics and New Drug Development, East China Normal University, Shanghai 200062, China;

*Corresponding Author

Prof. Zhiai Xu, E-mail: zaxu@chem.ecnu.edu.cn, Tel\&Fax: +86-21-54340053; Prof.

Wen Zhang, E-mail: wzhang@chem.ecnu.edu.cn, Tel\&Fax:+86-21-62235761. 


\section{Table of Contents}

Experimentals............................................................S-3

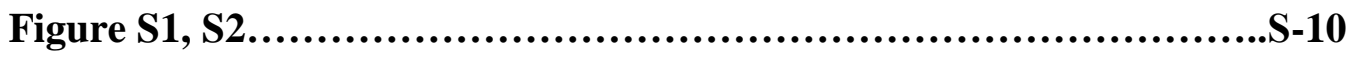

Figure S3, S4......................................................

Figure S5, S6......................................................S-12

Figure S7, S8, S9.................................................

Figure S10, S11....................................................S-14

Figure S12, S13...................................................S-15

Figure S14, S15....................................................

Figure S16, S17..................................................S-17

Figure S18, S19..................................................S-18

Figure S20, S21......................................................

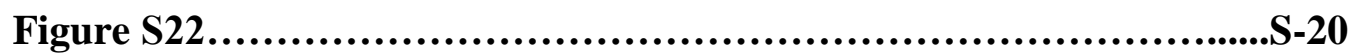

Figure S23, S24.....................................................21

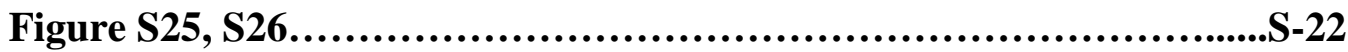

Figure S27.............................................................S-23

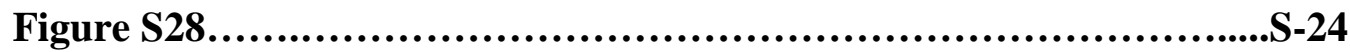

Figure S29..............................................................25

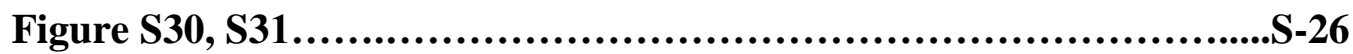

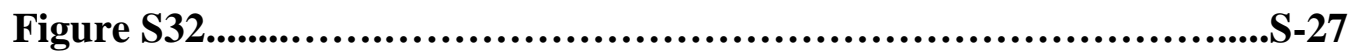

Figure S33, S34....................................................S-28

Figure S35, S36........................................................29

Figure S37, S38.........................................................

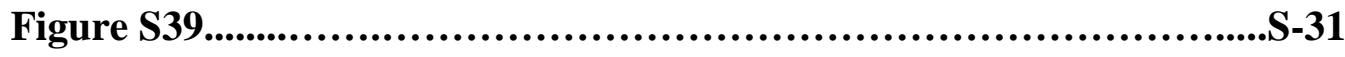




\section{Experimental section}

Materials. 4-Pentynoic acid and (2R,3S,4S,5R)-2-(acetoxymethyl)-6-(2-(2-(2azidoethoxy)ethoxy)ethoxy)tetrahydro-2H-pyran-3,4,5-triyl triacetate were purchased from Tokyo Chemical Industry Co., Ltd. (TCI); O²-(2,4-dinitrophenyl) 1-[(4ethoxycarbonyl)piperazin-1-yl]diazen-1-ium-1,2-diolate (JS-K) and etacrynic acid (EA) were purchased from Sigma-Aldrich (Shanghai, China); Fetal bovine serum (FBS), minimum Eagle's medium (MEM), RPMI media 1640, Dulbecco's modified Eagle's media Nutrient Mixture F-12 (DMEM/F-12) were purchased from Thermo Fisher Scientific Co. Ltd (Shanghai, China). Nitric oxide assay kit was purchased from Beyotime Biotechnology Co. Ltd (Shanghai, China); 3-(4,5-dimethylthiazol-2-yl)-2,5diphenyl-2h-tetrazoliubromide (MTT) and 4',6-diamidino-2-phenylindole (DAPI) were purchased from Shanghai Macklin Biochemical Co., Ltd (Shanghai, China); Annexin V-FITC/PI test kit and Calcein-AM/PI double stain kit were obtained from BD Biosciences (New Jersey, USA).

Instruments. ${ }^{1} \mathrm{H}$ and ${ }^{13} \mathrm{C}$ NMR spectrum were acquired with a Bruker Advance 500 $\mathrm{MHz}$ NMR spectrometer at $25^{\circ} \mathrm{C}$. HR-ESI mass spectra were acquired with Agilent 1290-6545 UHPLC-QTOF mass spectrometer. MALDI-TOF and Q-Exactive mass spectra were acquired with Bruker Autoflex Speed TOF/TOF mass spectrometer and Thermo Scientific ${ }^{\mathrm{TM}} \mathrm{Q}$ Exactive ${ }^{\mathrm{TM}}$ Orbitrap mass spectrometer, respectively. UV-vis and fluorescence spectra were acquired with Cary 60 spectrophotometer and Cary Eclipse spectrofluorophotometer, respectively (Agilent Technologies, Palo. Alto, CA, USA). The transmission electron microscopy (TEM) images were taken with JEM- 
2100F electron microscope (JEOL Ltd., Tokyo, Japan). Hydrodynamic diameters and zeta potential measurement were measured at $25^{\circ} \mathrm{C}$ using a Malvern Nanoseries (Malvern, England). MTT assays and fluorescence imaging were acquired with a Cytation 3 Cell Imaging Multi-Mode Reader (BioTek Instruments Inc. Winooski, VT, USA). The flow cytometry (FC) data was obtained using a Guava easyCyte 12 benchtop flow cytometer (Merck Millipore, Germany). Confocal laser scanning microscopy (CLSM) were acquired with a Leica TCS-SP8 confocal scanning microscope using a $63 \times$ oil objective and a numerical aperture of 1.40 (Leica Microsystem Inc., Wetzlar, Germany).

Synthesis of $\quad(3 R, 4 S, 5 R, 6 R)-2-(2-(2-(2-a z i d o e t h o x y) e t h o x y) e t h o x y)-6-$ (hydroxymethyl)tetrahydro-2H-pyran-3,4,5-triol (compound 1).

To a solution of 2-[2-(2-azidoethoxy)ethoxy]ethyl 2,3,4,6-tetra-O-acetyl-Dgalactopyranoside $(350.0 \mathrm{mg}, 0.69 \mathrm{mmol})$ in $5.0 \mathrm{~mL}$ of mixed solvent $\left(\mathrm{THF} / \mathrm{H}_{2} \mathrm{O}=3: 2\right.$ v/v) was added $\mathrm{LiOH}(83.0 \mathrm{mg}, 3.46 \mathrm{mmol})$ at room temperature. The resulting mixture was stirred for $6 \mathrm{~h}$. The mixture is dried in vacuum to remove the solvent. The residue was purified by chromatography on silica gel column $\left(\mathrm{CH}_{2} \mathrm{Cl}_{2} / \mathrm{MeOH}=20: 1 \mathrm{v} / \mathrm{v}\right)$ to furnish the desired compound 1 as colorless oil (216.0 mg, 93\% yield). ${ }^{1} \mathrm{H}$ NMR (500 $\left.\mathrm{MHz}, \mathrm{CDCl}_{3}\right) \delta 4.73-4.36(\mathrm{~m}, 2 \mathrm{H}), 4.33(\mathrm{~d}, \mathrm{~J}=6.7 \mathrm{~Hz}, 1 \mathrm{H}), 4.28-4.09(\mathrm{~m}, 1 \mathrm{H}), 4.05$ $(\mathrm{dd}, \mathrm{J}=12.8,6.0 \mathrm{~Hz}, 2 \mathrm{H}), 3.84(\mathrm{~d}, \mathrm{~J}=5.2 \mathrm{~Hz}, 2 \mathrm{H}), 3.80-3.59(\mathrm{~m}, 10 \mathrm{H}), 3.56(\mathrm{t}, \mathrm{J}=$ $5.4 \mathrm{~Hz}, 1 \mathrm{H}), 3.49-3.36(\mathrm{~m}, 2 \mathrm{H}), 2.59-2.09(\mathrm{~m}, 2 \mathrm{H}) .{ }^{13} \mathrm{C} \mathrm{NMR}\left(126 \mathrm{MHz}, \mathrm{CDCl}_{3}\right) \delta$ $103.55,74.32,73.39,71.20,70.48,70.31,69.92,68.94,68.67,61.52,50.65$. HRMS (ESI): calcd for $\mathrm{C}_{12} \mathrm{H}_{23} \mathrm{~N}_{3} \mathrm{NaO}_{8}[\mathrm{M}+\mathrm{Na}]^{+} \mathrm{m} / \mathrm{z}$ 360.1485; found 360.1384. 


\section{Encapsulation Ratio of JS-K.}

First, the standard curves for concentrations and the integral absorption peak areas of GalNONP and JS-K were determined by HPLC (Eclipse XDB-C18, $5 \mu \mathrm{m}, 4.6 \times 250$ $\mathrm{mm}$, mobile phase: $75 \% \mathrm{MeCN}, 25 \%$ DI water, flow velocity: $0.5 \mathrm{~mL} / \mathrm{min}$, absorption detection wavelength: $300 \mathrm{~nm}$ ). The retention time of GalNONP and JS-K were $3.7 \mathrm{~min}$ and $7.2 \mathrm{~min}$, respectively. The dialyzed micelle solution was determined by HPLC to calculate concentrations of GalNONP and JS-K, respectively. The encapsulation ratio was calculated by theoretical and test mole ratios of JS-K to GalNONP. In addition, in the presence of high concentration of glutathione (GSH), the concentration of JS-K was also measured by the same method.

\section{Response of GalNONP to NO under Different $\mathrm{pH}$ and Biological Interferences. NO gas}

was obtained by heating dilute nitric acid with copper and then NO saturated solution was obtained by bubbling into deoxygenated water for at least $30 \mathrm{~min}$. The concentration of NO in saturated solution was tested by Griess Method, and make sure NO saturated solution used in each experiment was new-made. GalNONP micellar stock solution was diluted to $100 \mu \mathrm{M}$ by PB buffer with different $\mathrm{pH}$. Finally, $50 \mu \mathrm{L}$ above GalNONP solution, $30 \mu \mathrm{L} 1 \mathrm{mM}$ NO solution and $20 \mu \mathrm{L} \mathrm{MeCN}$ were mixed together and placed in a shaking box under $37^{\circ} \mathrm{C}$ for $1.5 \mathrm{~h}$.

GSH, L-cysteine (Cys), L-lysine (Lys), $\mathrm{K}^{+}, \mathrm{Na}^{+}, \mathrm{Ca}^{2+}, \mathrm{Fe}^{2+}, \mathrm{Fe}^{3+}, \mathrm{Zn}^{2+}, \mathrm{Mg}^{2+}, \mathrm{NO}_{2}^{-}, \mathrm{NO}_{3}^{-}$, $\cdot \mathrm{OH}, \mathrm{ClO}^{-}$, tert-butyl hydrogen peroxide (TBHP), $\mathrm{H}_{2} \mathrm{O}_{2}, \mathrm{O}_{2}{ }^{-},{ }^{1} \mathrm{O}_{2}$, ONOO ${ }^{-}$were preprepared to $3.33 \mathrm{mM}$ fresh stock solution. GSH, Cys, $\mathrm{Lys}^{\mathrm{ClO}}{ }^{-}$, TBHP and $\mathrm{H}_{2} \mathrm{O}_{2}$ were made by dissolving solids or dilute liquids. $\mathrm{K}^{+}, \mathrm{Na}^{+}, \mathrm{Ca}^{2+}, \mathrm{Fe}^{2+}, \mathrm{Fe}^{3+}, \mathrm{Zn}^{2+}$ and $\mathrm{Mg}^{2+}$ were prepared by 
dissolving the corresponding chlorinated salt, respectively. $\mathrm{NO}_{2}{ }^{-}$and $\mathrm{NO}_{3}{ }^{-}$were acquired by dissolving $\mathrm{NaNO}_{2}$ and $\mathrm{NaNO}_{3}$ solid, respectively. Hydroxyl radical $(\cdot \mathrm{OH})$ was generated by Fenton reaction $\left(\mathrm{Fe}^{2+} / \mathrm{H}_{2} \mathrm{O}_{2}\right)$. Superoxide anion $\left(\mathrm{O}_{2}{ }^{-}\right)$was acquired from $\mathrm{KO}_{2}$ in DMSO. Singlet oxygen $\left({ }^{1} \mathrm{O}_{2}\right)$ was formulated by the reaction of $\mathrm{ClO}^{-}$and $\mathrm{H}_{2} \mathrm{O}_{2}$. Peroxynitrite (ONOO ${ }^{-}$) was generated by $\mathrm{NaNO}_{2}$ and $\mathrm{H}_{2} \mathrm{O}_{2}$. Finally, $50 \mu \mathrm{L}$ above GalNONP/C solution, $15 \mu \mathrm{L} 2 \mathrm{mM}$ NO solution, $15 \mu \mathrm{L}$ biological interference solution and $20 \mu \mathrm{L}$ MeCN were mixed together and placed in a shaking box under $37^{\circ} \mathrm{C}$ for $1.5 \mathrm{~h}$.

\section{Cell Culture.}

Hela human cervical cancer cells, L929 mouse fibroblasts cells, A549 human lung adenocarcinoma cells, CT26 mouse colon cancer cells and HepG2 human hepatoma carcinoma cells were acquired from the cell bank of the Chinese Academy of Sciences (Shanghai, China). Hela and HepG2 cells were cultured in minimum Eagle's medium (MEM). L929 and CT26 cells were cultured in RPMI media 1640. A549 cells were cultured in Dulbecco's modified Eagle's media Nutrient Mixture F-12 (DMEM/F-12). All cells were maintained in medium that supplemented with $10 \% \mathrm{FBS}, 1 \%$ penicillin, and $1 \%$ streptomycin and then grown to the required density in a cell culture incubator at $37^{\circ} \mathrm{C}$ and humidified atmosphere with $5 \% \mathrm{CO}_{2}$.

\section{Cell Uptake of GalNONP.}

For fluorescence imaging, Hela, L929, A549, CT26 and HepG2 cells were seeded at $2 \times 10^{5}$ cells into each well of 24-well plates and incubated overnight. The original medium was removed and fresh medium with $100 \mu \mathrm{M}$ GalNONP was added to each well for another onehour incubation. Finally, cells were washed with $1 \times$ PBS three times and green fluorescence 
was observed with a Cytation 3 Cell Imaging Multi-Mode Reader. For flow cytometry examination, the incubation time of all kinds of cells with GalNONP was extended from 0$180 \mathrm{~min}$. Then $400 \mu \mathrm{L}$ cell suspension was acquired after trypsinization and wash. At last, average fluorescence intensity of each cell was detected by a flow cytometry.

\section{Galactose Inhibition.}

HepG2 cells were seeded at $10^{5}$ cells into each well of 24 -well plates and incubated until the cells were attached well to the bottom of the plate. When cells were preincubated with different concentrations of galactose for 2 hours, $25 \mu \mathrm{M}$ GalNONP was added into each well for 10 min incubation after changing culture medium. Finally, cells were washed three times with $1 \times$ PBS buffer and observed with a Cytation 3 cell imaging multi-mode reader.

\section{Efficacy Evaluation of GalNONP/C by Griess and MTT Assay.}

HepG2 cells were seeded at $10^{4}$ cells/well into $6 \times 8$ wells of 96 -well plates and incubated overnight. GalNONP, GalNONP/C and JS-K was added and incubated for different times, respectively. The concentration of GalNONP/C was $50 \mu \mathrm{M}$, while the addition amount of GalNONP and JS-K was equivalent to that in GalNONP/C group, respectively. Griess reagent I $(20 \mu \mathrm{L})$ and Griess reagent II $(20 \mu \mathrm{L})$ was mixed with 20 $\mu \mathrm{L}$ cell culture medium from each well for $10 \mathrm{~min}$ and kept in dark before absorption measurement at $540 \mathrm{~nm}$ by a microtiter plate reader. Culture medium alone was used as control. Meanwhile, different concentrations of $\mathrm{NaNO}_{2}$ was added into each well to get standard curves and equation of linear regression.

HepG2 cells were seeded at $5 \times 10^{3}$ cells each well into $96-$-well plates and incubated 
for 24 h. Cells were treated with different concentrations of GalNONP, GalNONP/C and JS-K, respectively. After $24 \mathrm{~h}$ incubation, the culture media were removed and then each well was added with $100 \mu \mathrm{L}$ of $0.5 \mathrm{mg} / \mathrm{mL}$ MTT which was dissolved in $1 \times \mathrm{PBS}$. After another $4 \mathrm{~h}$ incubation at $37^{\circ} \mathrm{C}$, the supernatant was removed carefully, then 150 $\mu \mathrm{L}$ DMSO was added to each well. After shaking for $20 \mathrm{~min}$, the absorbance of each well was measured at $490 \mathrm{~nm}$ by a microtiter plate reader.

\section{CLSM Imaging and Apoptosis Analysis by FC.}

HepG2 cells were grown in a 4-chamber glass bottom dish at the environment of $37^{\circ} \mathrm{C}$, $5 \% \mathrm{CO}_{2}$ for at least $12 \mathrm{~h}$ for the appropriate confluence. After preincubated with $50 \mu \mathrm{M}$ GalNONP/C for $1 \mathrm{~h}$, cells were exchanged with fresh drug-free culture medium for 0 , 6 and $12 \mathrm{~h}$ incubation. Then, cells were washed with $1 \times \mathrm{PBS}$ three times and monitored by a confocal scanning microscope for efficacy detection.

For apoptosis analysis, HepG2 cells were seeded at $2 \times 10^{5}$ cells into each well of 24-well plates and incubated overnight. After the same operation like CLSM imaging, cells were made to suspension after trypsinization and then dealt with Annexin VFITC/PI test kit. The detection of average fluorescence intensity needed be finished within 20 min by a microflow cytometry.

GST $\boldsymbol{\pi}$ Inhibition by EA. HepG2 cells were grown in a 4-chamber glass bottom dish at the environment of $37^{\circ} \mathrm{C}, 5 \% \mathrm{CO}_{2}$ for at least $12 \mathrm{~h}$ for the appropriate confluence. Then HepG2 cells were preincubated with $0,25,50$ and $100 \mu \mathrm{M}$ EA for $2 \mathrm{~h}$. Next, 50 $\mu \mathrm{M}$ GalNONP/C was incubated with cells for $1 \mathrm{~h}$. During another 6-hour waiting, cells were cultured in drug-free fresh medium. Before observation on a confocal scanning 
microscope, cells were stained with $10 \mu \mathrm{g} / \mathrm{mL}$ DAPI for $15 \mathrm{~min}$ and washed by $1 \times \mathrm{PBS}$ three times.

Ex Vivo Imaging. The HCC orthotopic transplantation Balb/c-nu-nu mice and normal Balb/c-nu-nu mice were sacrificed by cervical dislocation. Livers were taken out and cut into $4 \mu \mathrm{m}$-thick slices. The slices were used immediately for the following experiments. (i) HCC liver tissue sections were incubated with $100 \mu \mathrm{M}$ GalNONP; (ii) HCC liver tissue sections were incubated with $100 \mu \mathrm{M}$ GalNONP/C; (iii) normal liver tissue sections were incubated with $100 \mu \mathrm{M}$ GalNONP/C. After $1 \mathrm{~h}$ incubation, GalNONP or GalNONP/C were washed off. Another 12 hours was needed in the incubator, liver tissue sections were observed by a Cytation 3 cell imaging multi-mode reader after stained with $10 \mu \mathrm{g} / \mathrm{mL}$ DAPI. 


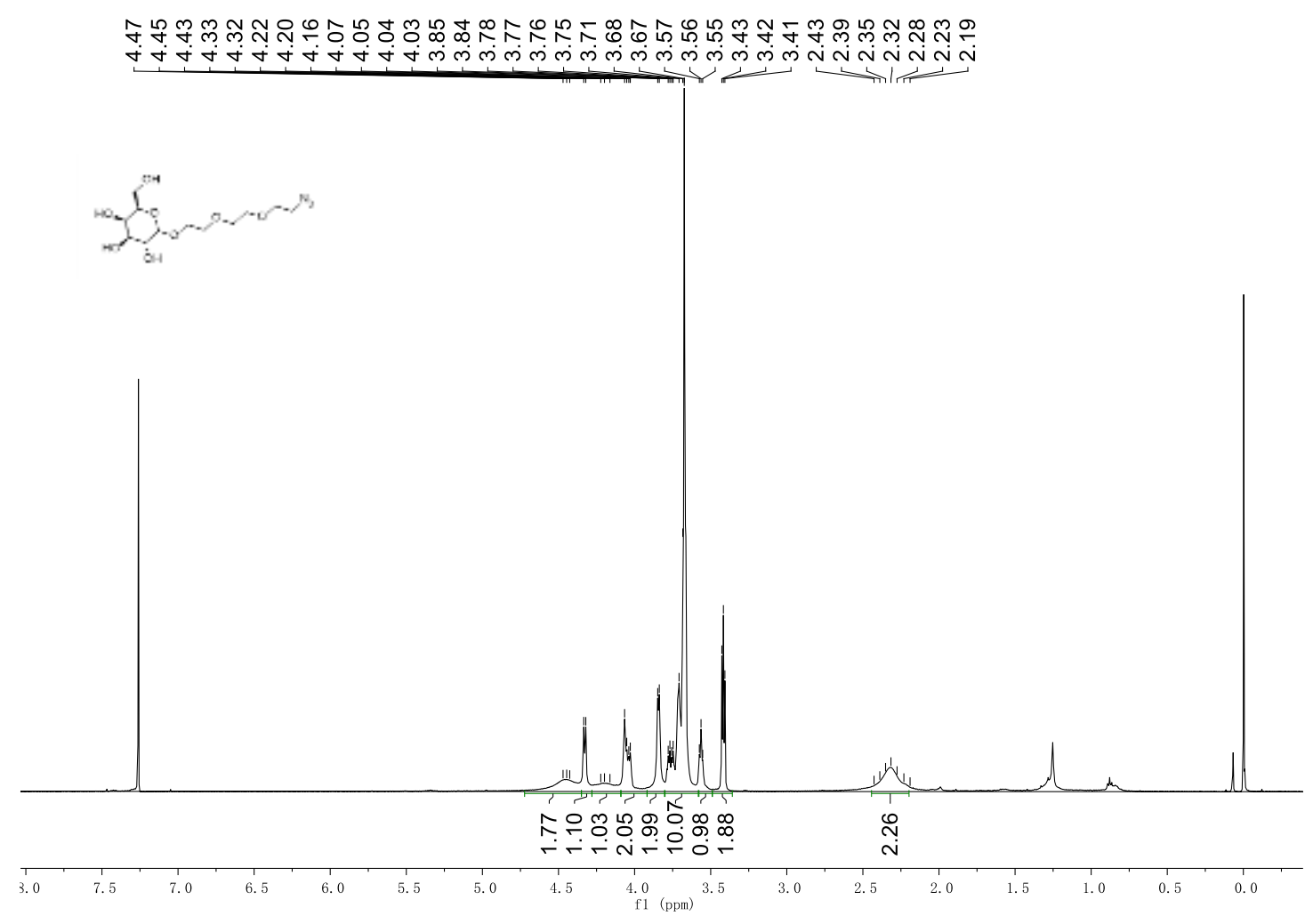

Figure S1. ${ }^{1} \mathrm{H}$ NMR spectrum of compound 1 in $\mathrm{CDCl}_{3}$.

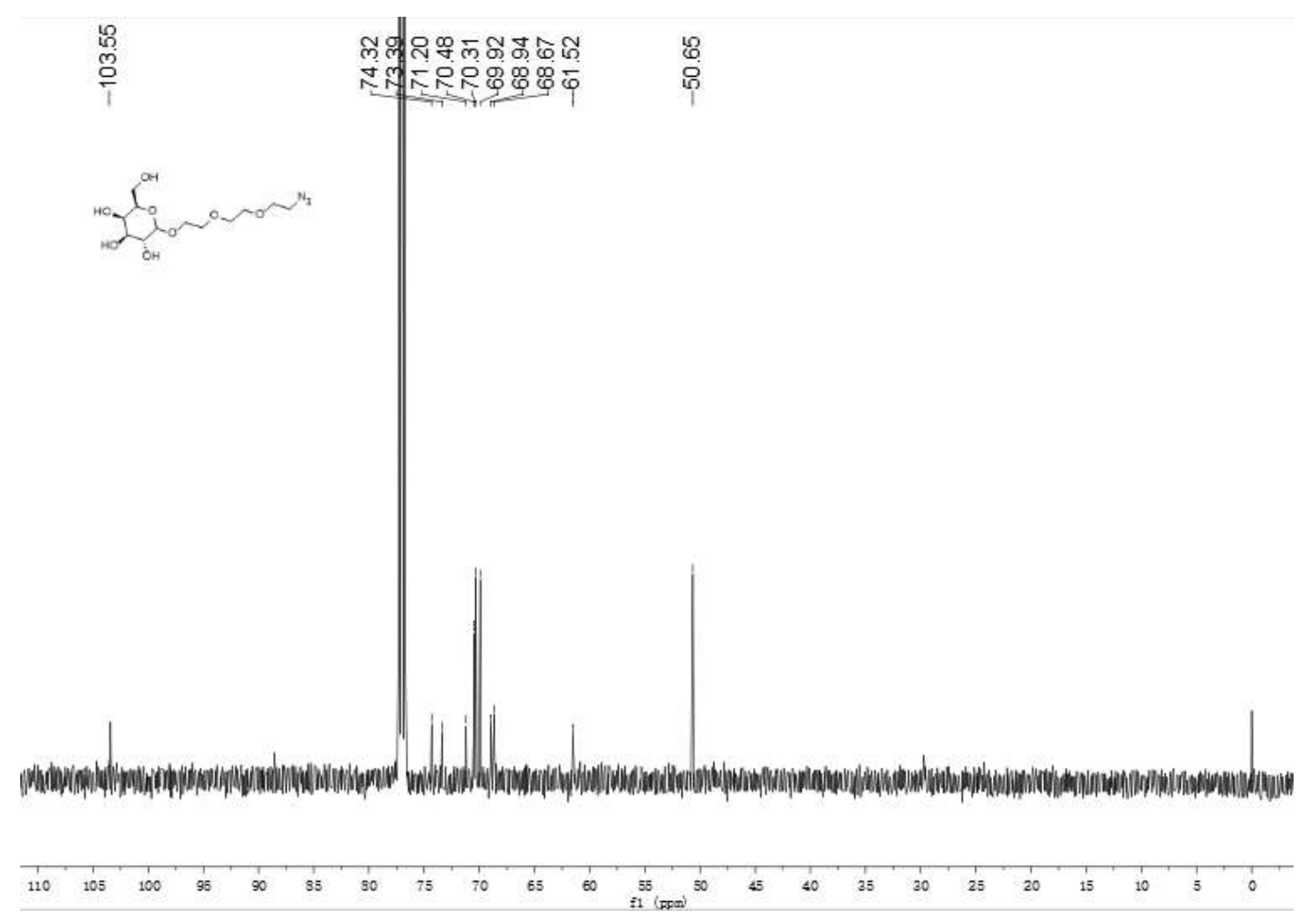

Figure S2. ${ }^{13} \mathrm{C}$ NMR spectrum of compound 1 in $\mathrm{CDCl}_{3}$. 


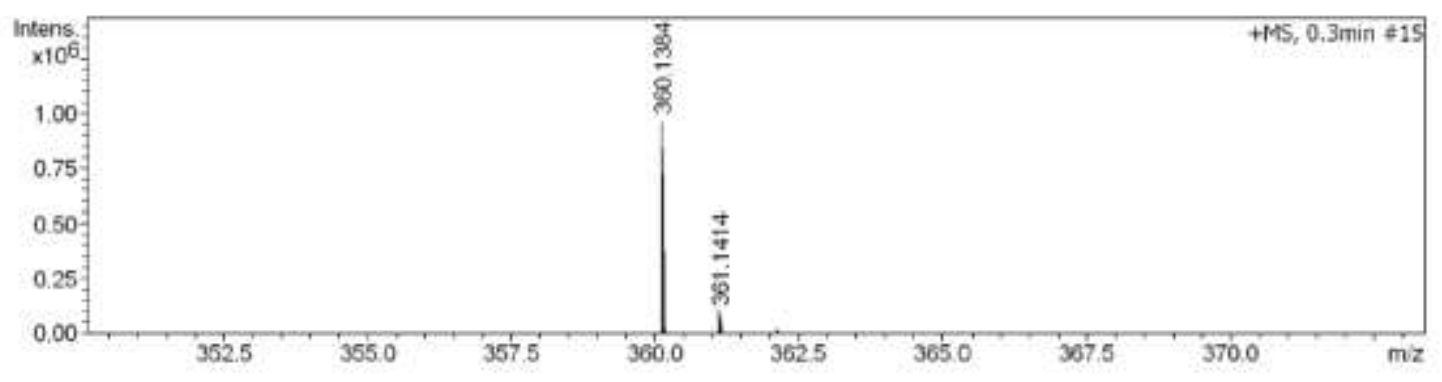

Figure S3. HR-ESI-MS of compound 1.
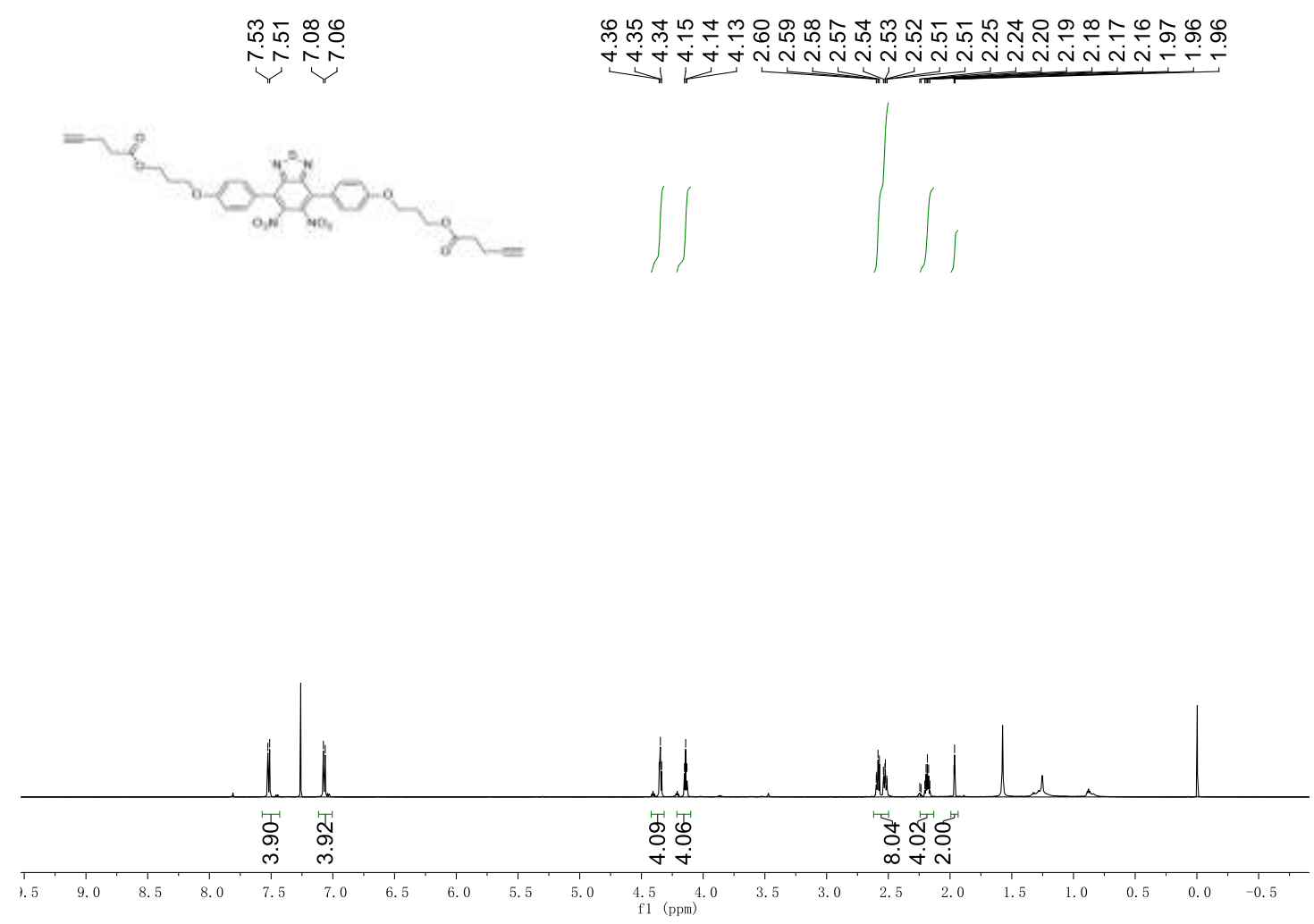

Figure S4. ${ }^{1} \mathrm{H}$ NMR spectrum of compound $3 \mathrm{a}$ in $\mathrm{CDCl}_{3}$. 

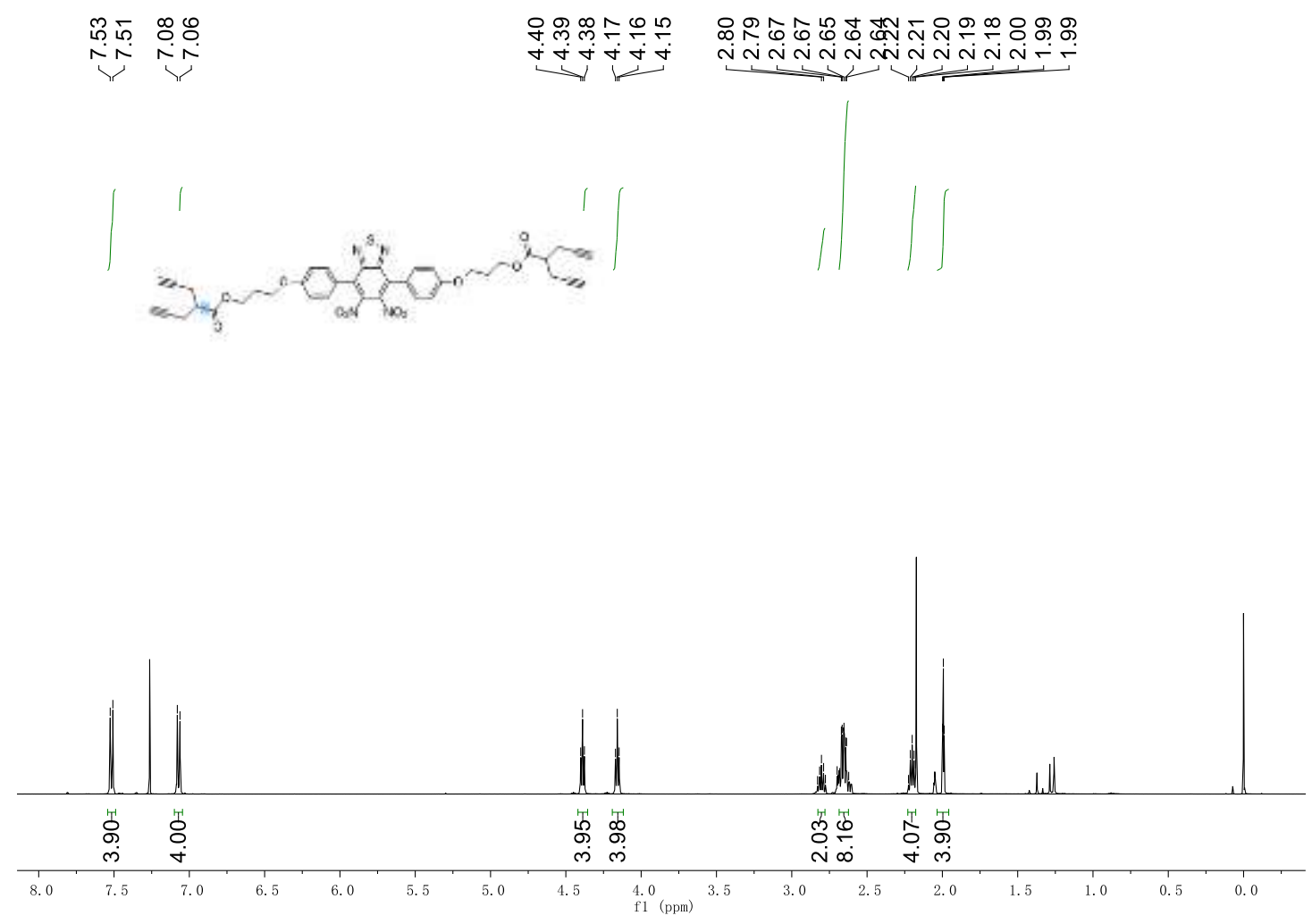

Figure S5. ${ }^{1} \mathrm{H}$ NMR spectrum of compound $3 b$ in $\mathrm{CDCl}_{3}$.

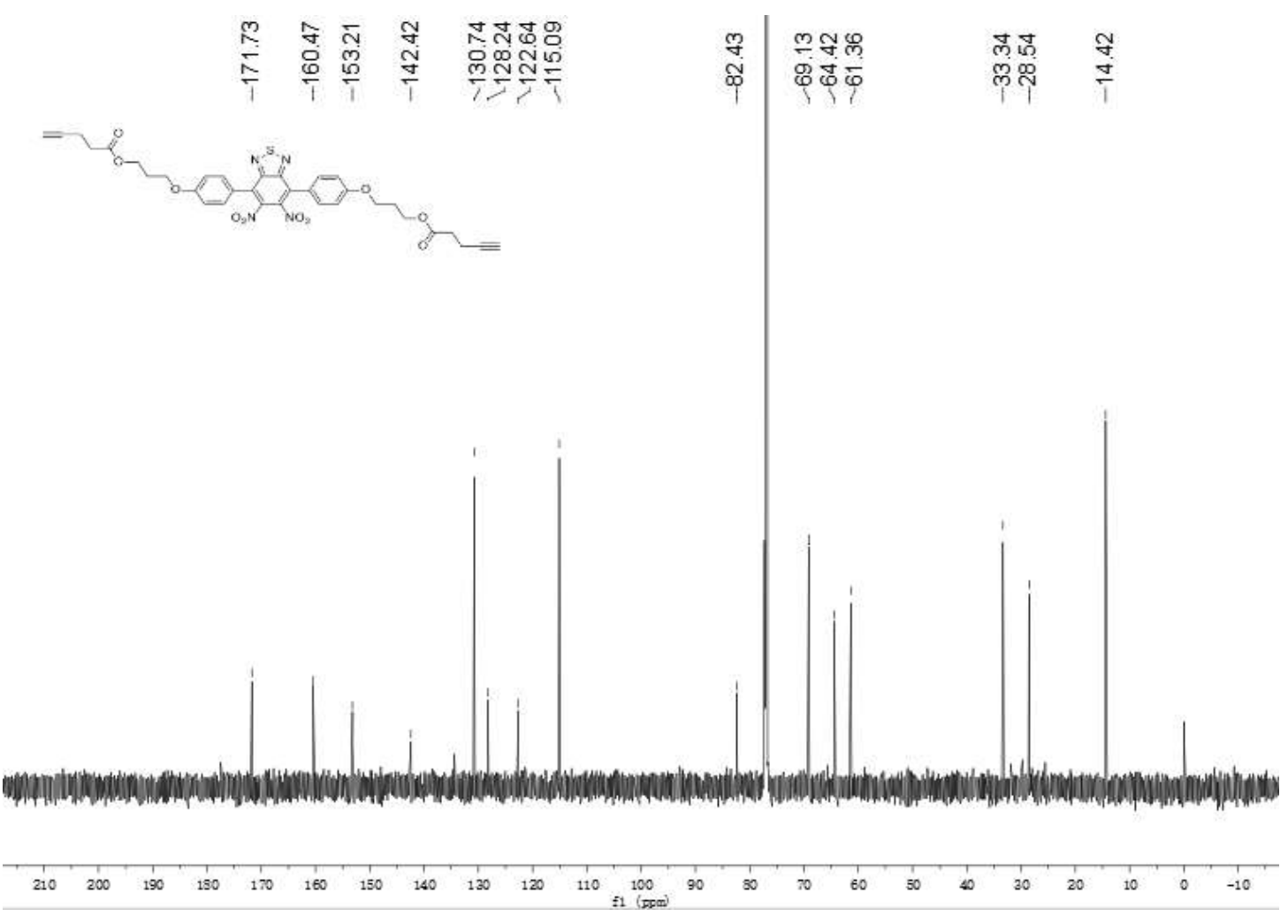

Figure S6. ${ }^{13} \mathrm{C}$ NMR spectrum of compound $3 \mathrm{a}$ in $\mathrm{CDCl}_{3}$. 


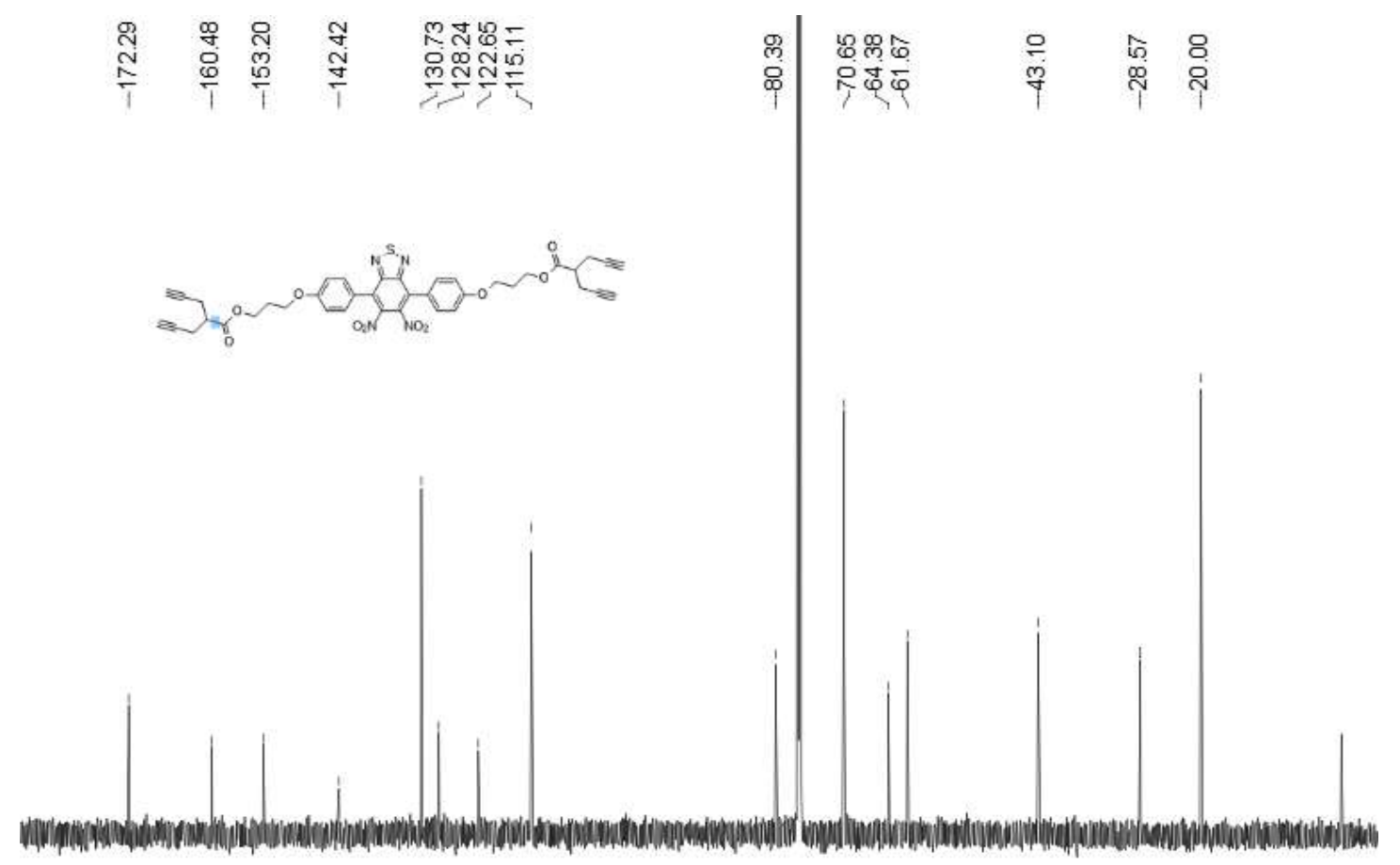

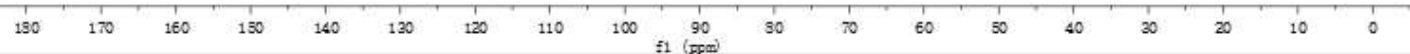

Figure S7. ${ }^{13} \mathrm{C}$ NMR spectrum of compound $3 \mathrm{~b}$ in $\mathrm{CDCl}_{3}$.

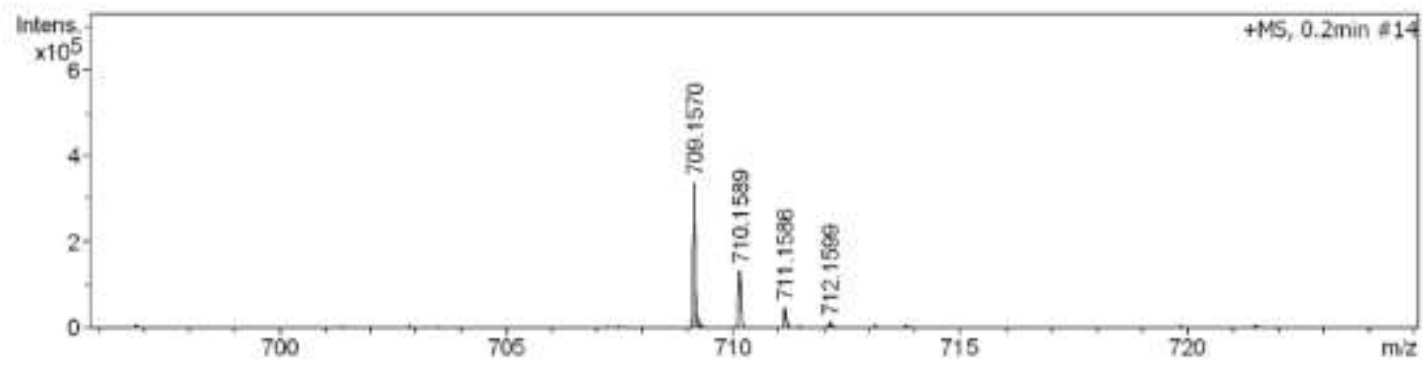

Figure S8. HR-ESI-MS of compound 3a.

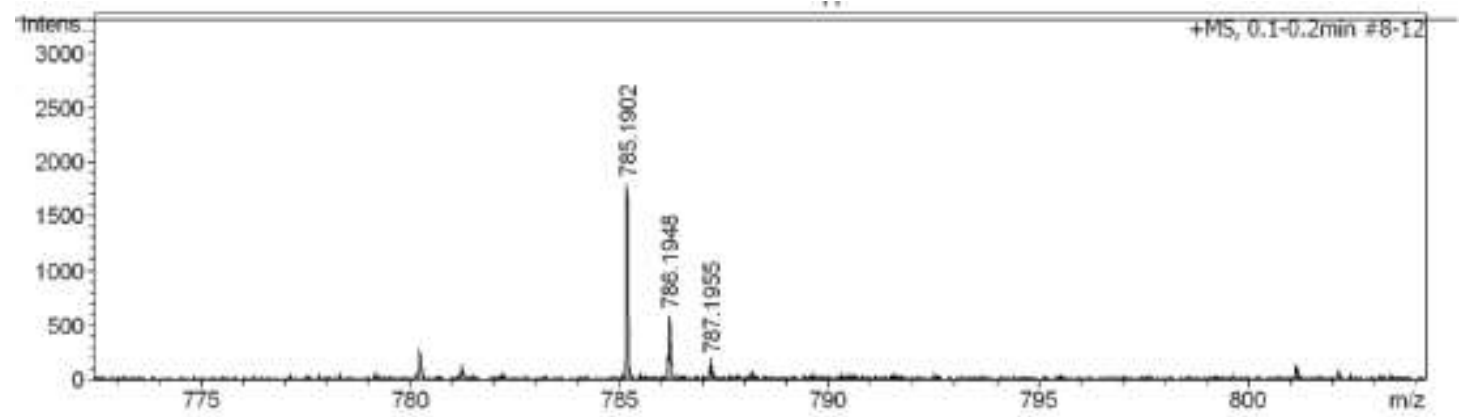

Figure S9. HR-ESI-MS of compound 3b. 


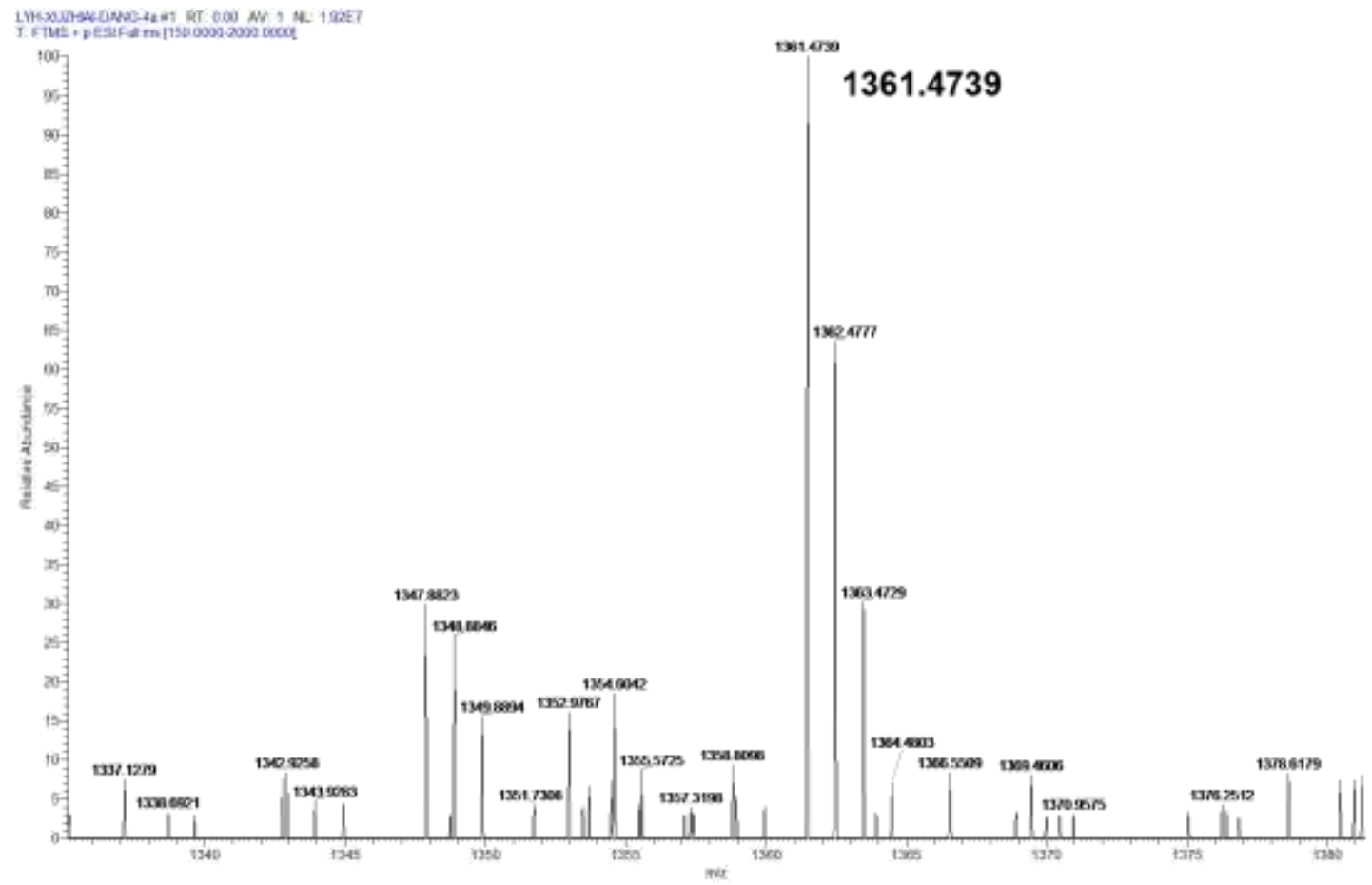

Figure S10. Q-Exactive mass spectrum of compound 4a.

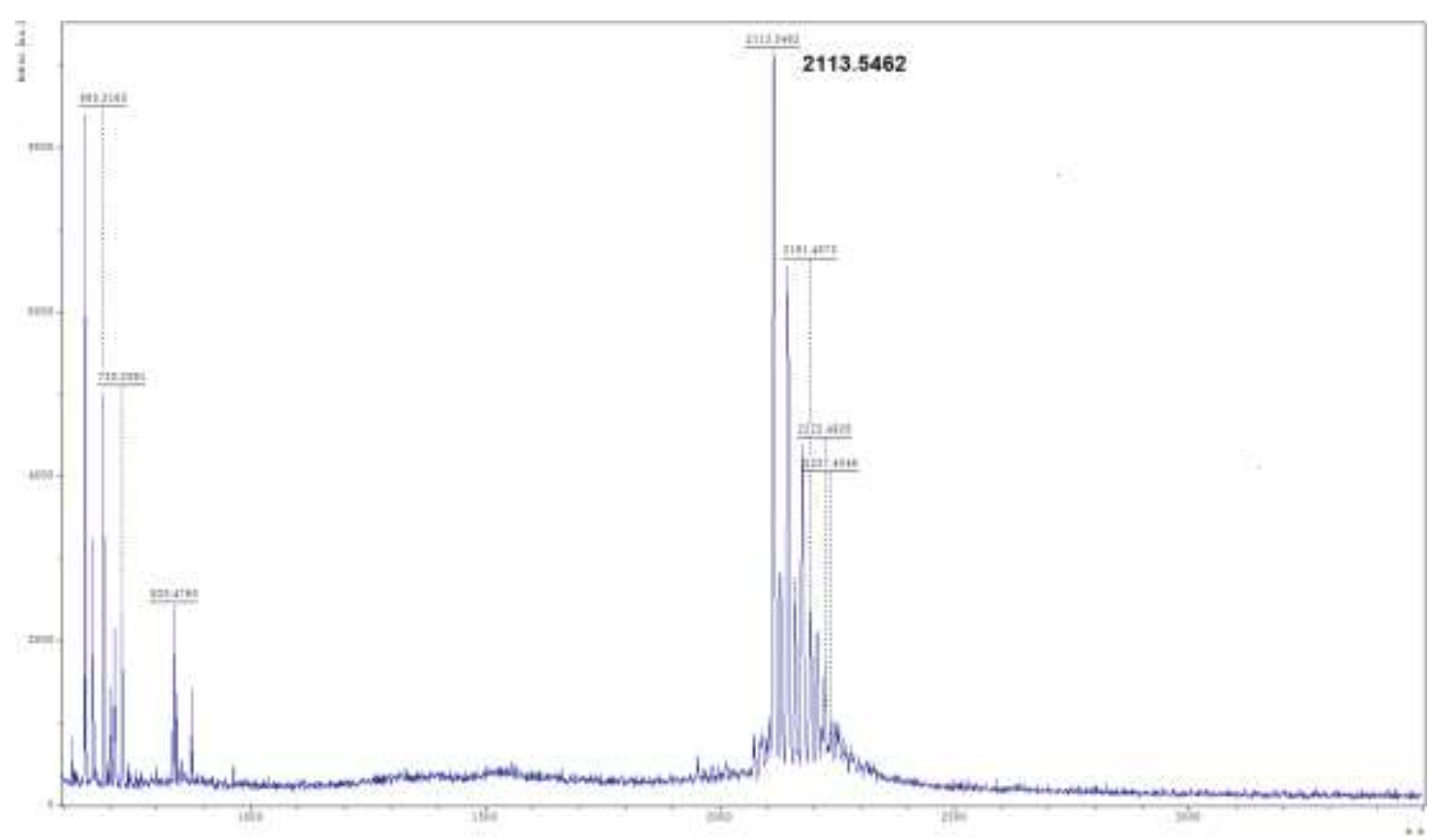

Figure S11. MALDI-TOF mass spectrum of compound 4b. 


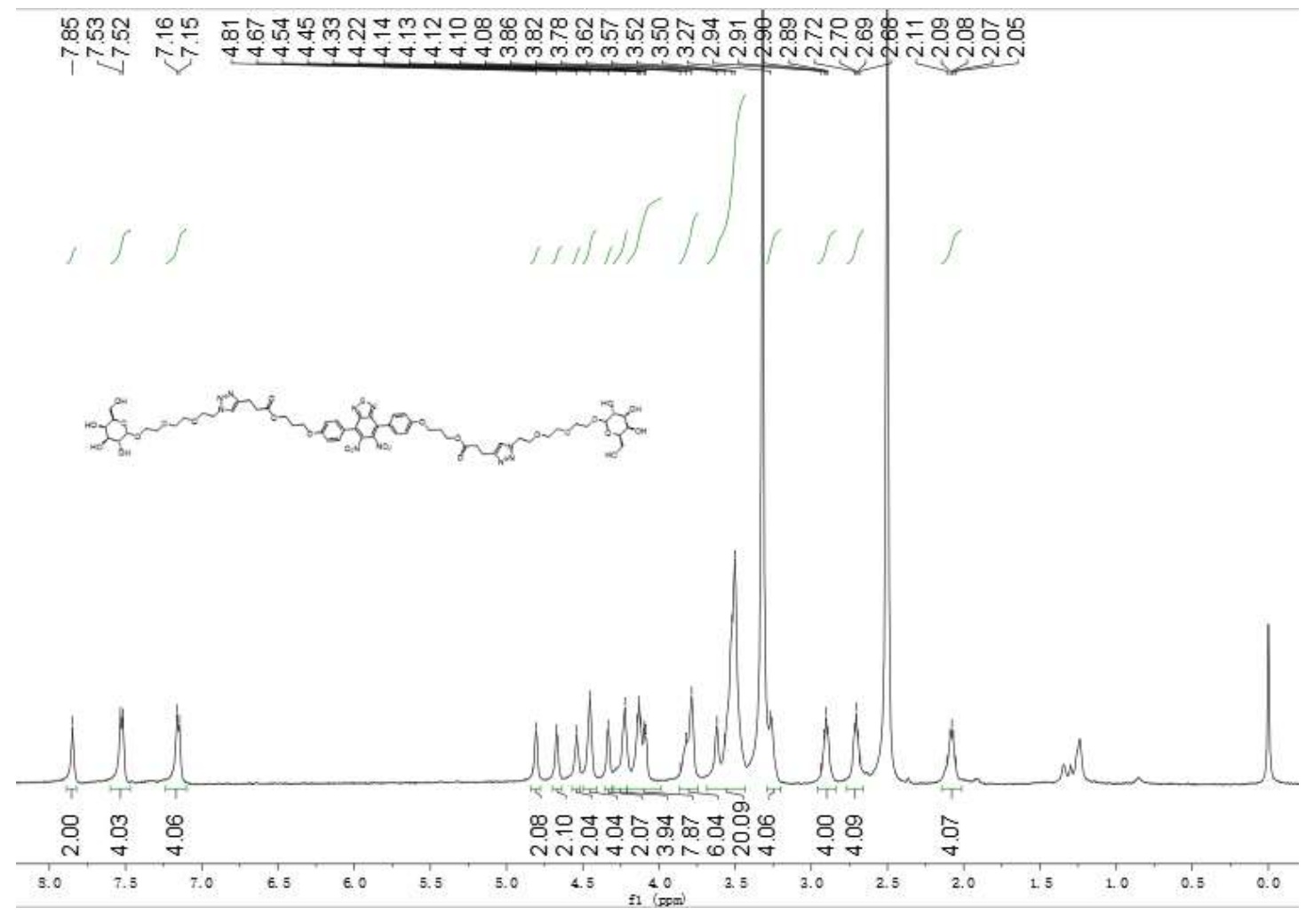

Figure S12. ${ }^{1} \mathrm{H}$ NMR spectrum of compound $4 \mathrm{a}$ in DMSO- $d_{6}$.

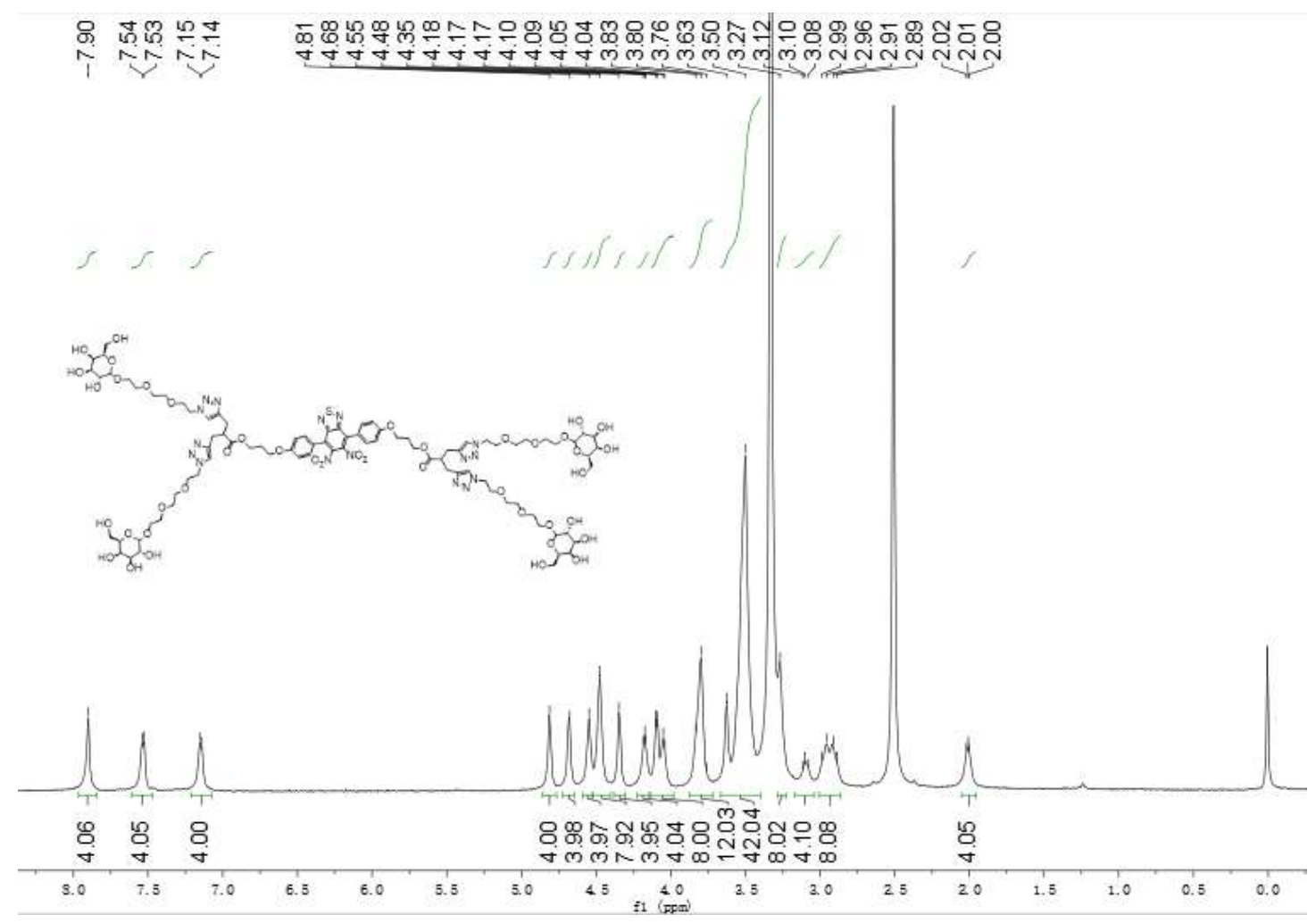

Figure S13. ${ }^{1} \mathrm{H}$ NMR spectrum of compound $4 \mathrm{~b}$ in DMSO- $d_{6}$. 


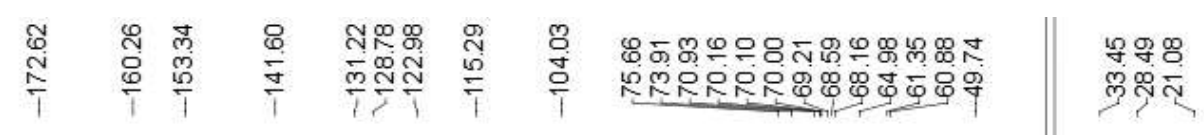
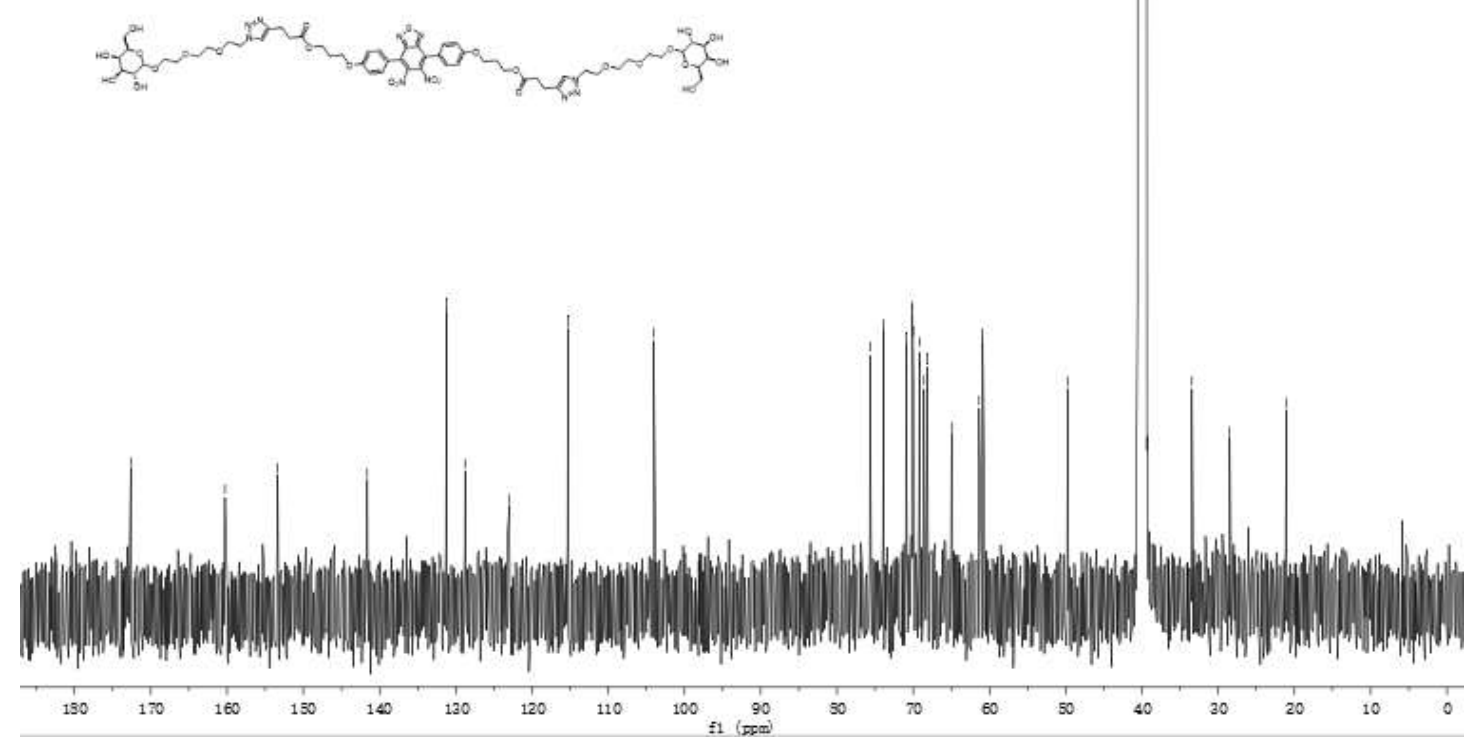

Figure S14. ${ }^{13} \mathrm{C}$ NMR spectrum of compound 4a in DMSO- $d_{6}$.

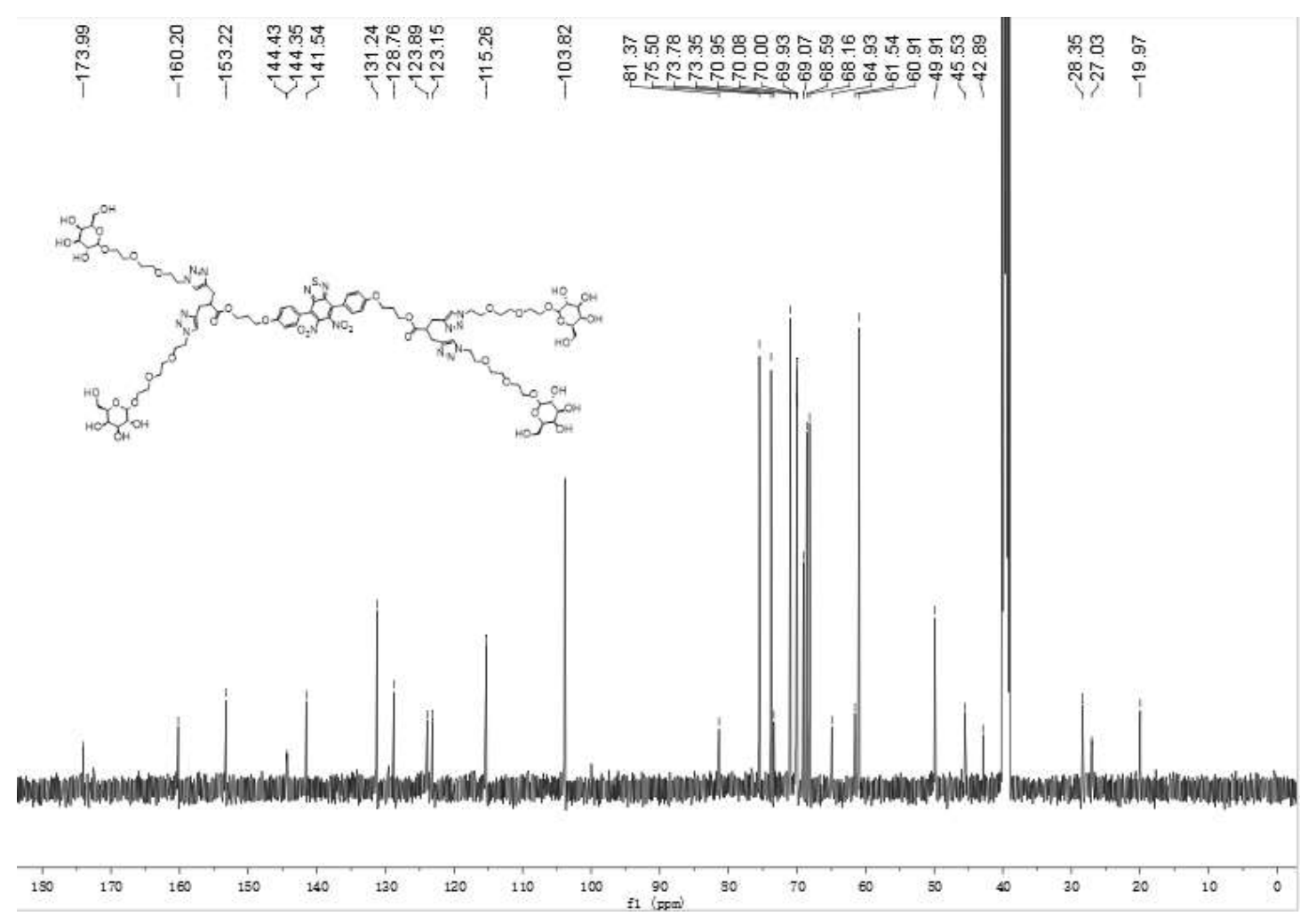

Figure S15. ${ }^{13} \mathrm{C}$ NMR spectrum of compound $4 \mathrm{~b}$ in DMSO- $d_{6}$. 


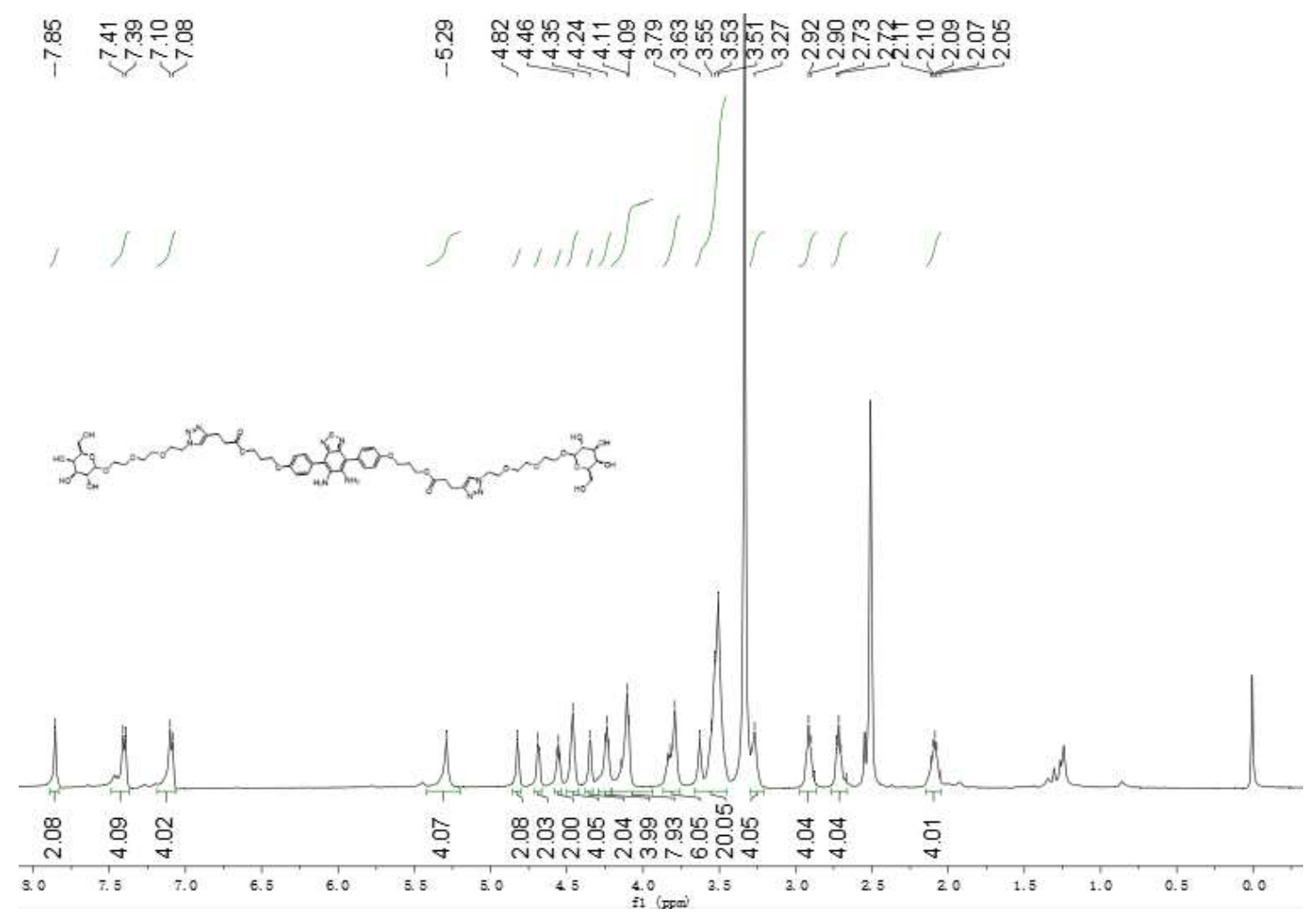

Figure S16. ${ }^{1} \mathrm{H}$ NMR spectrum of $d i$-GalNOP in DMSO- $d_{6}$.

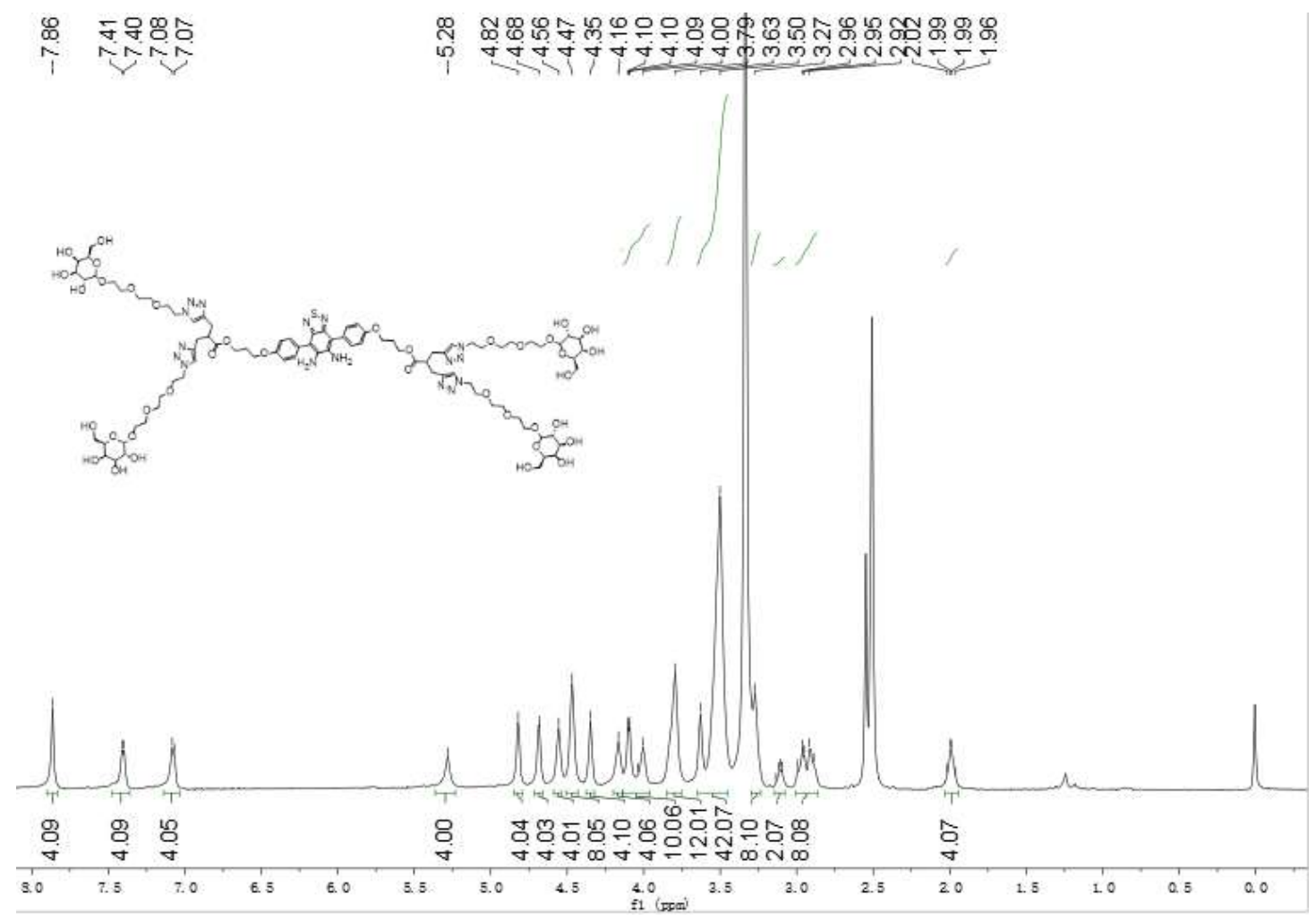

Figure S17. ${ }^{1} \mathrm{H}$ NMR spectrum of tetra-GalNOP in DMSO- $d_{6}$. 


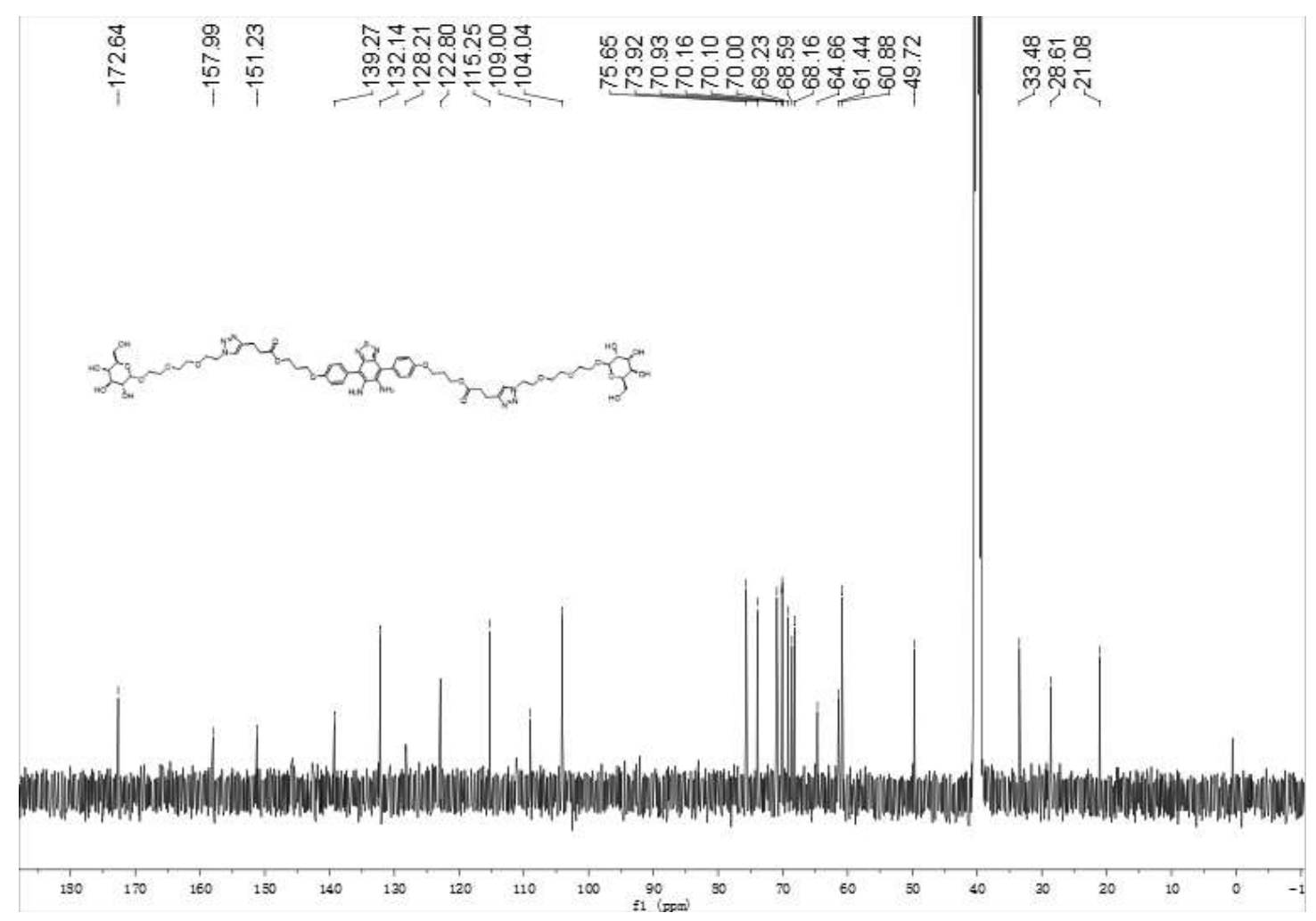

Figure S18. ${ }^{13} \mathrm{C}$ NMR spectrum of $d i$-GalNOP in DMSO- $d_{6}$.

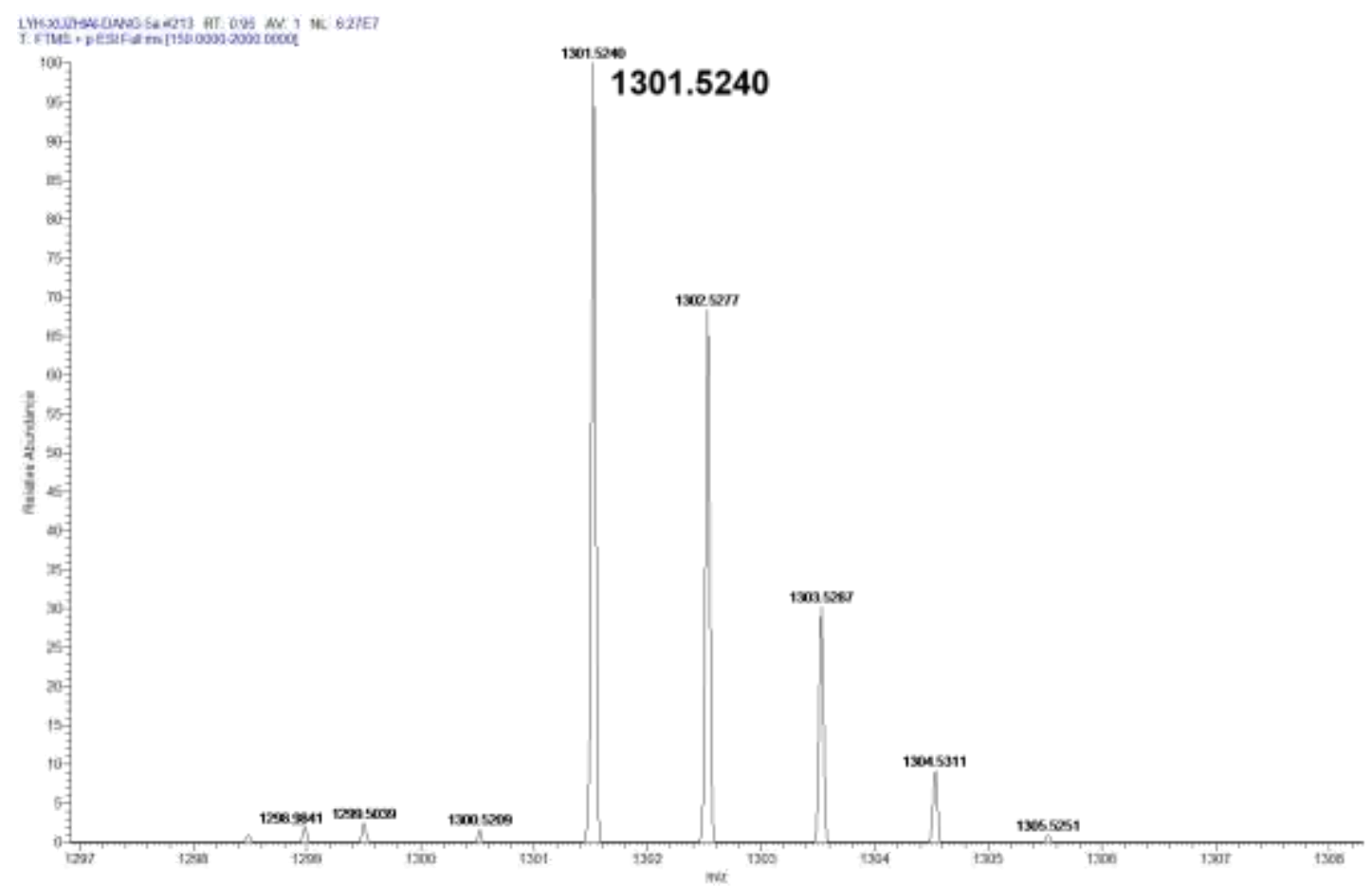

Figure S19. Q-Exactive mass spectrum of $d i$-GalNOP. 


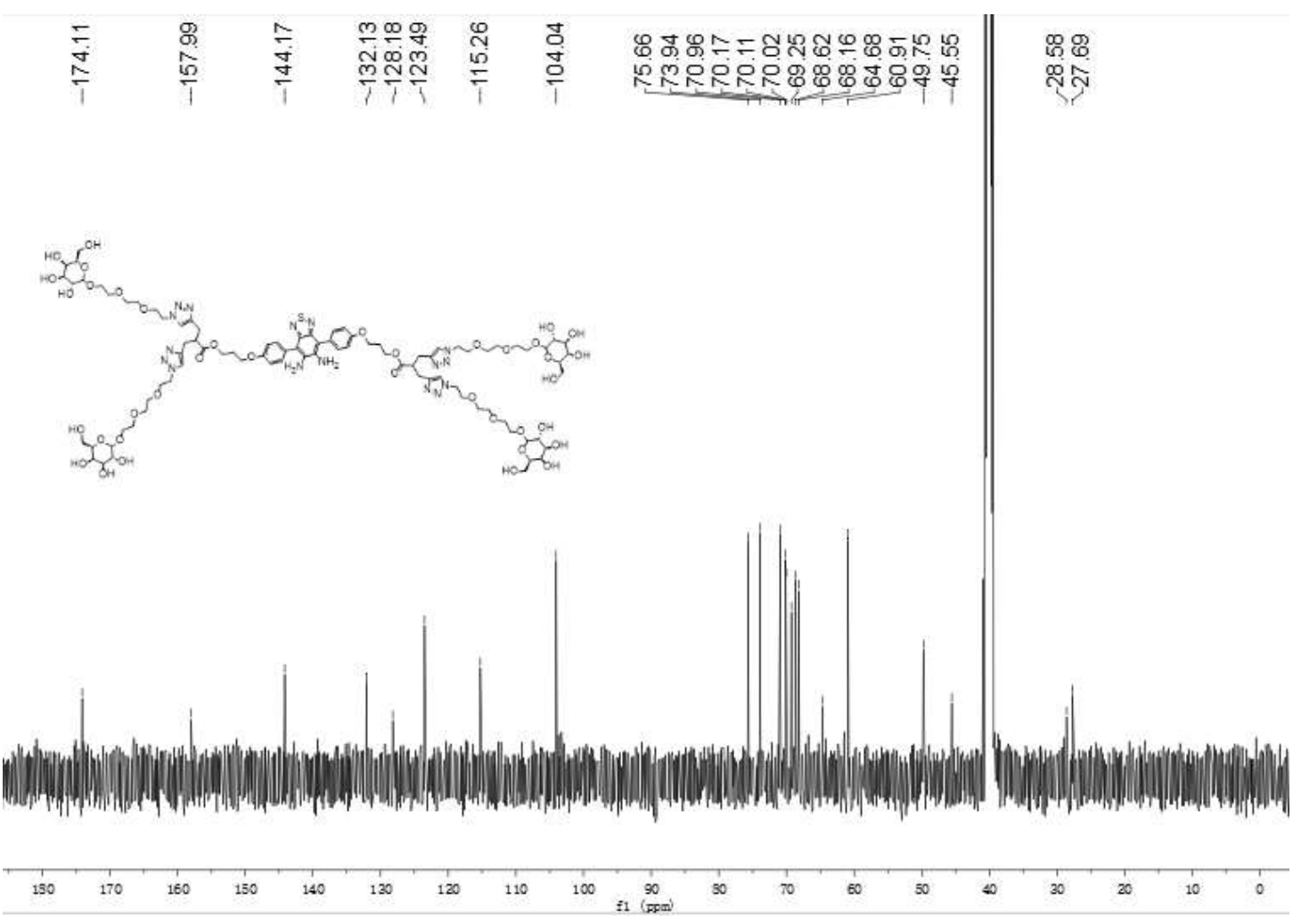

Figure S20. ${ }^{13} \mathrm{C}$ NMR spectrum of tetra-GalNOP in DMSO- $d_{6}$.

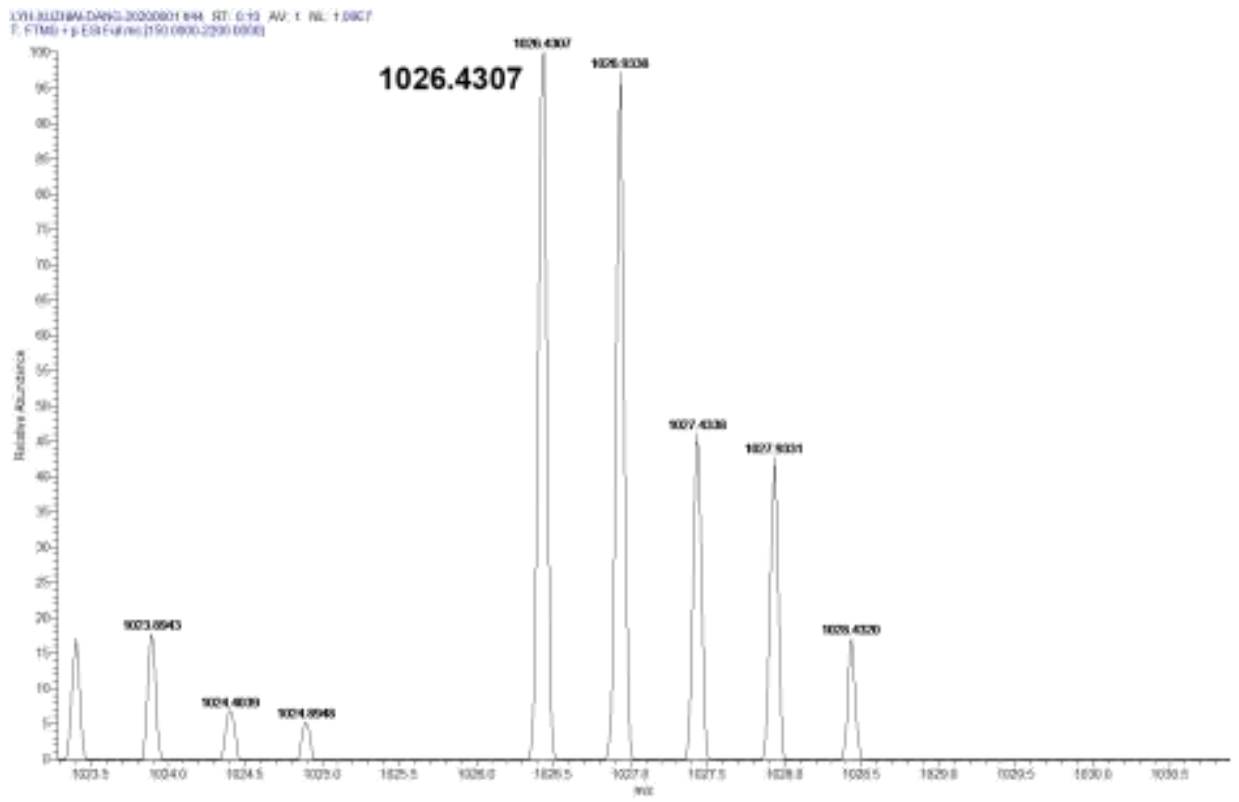

Figure S21. Q-Exactive mass spectrum of tetra-GalNOP. 
A

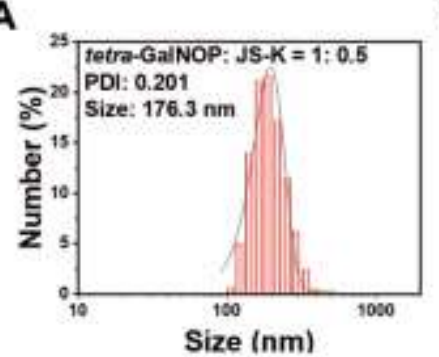

B

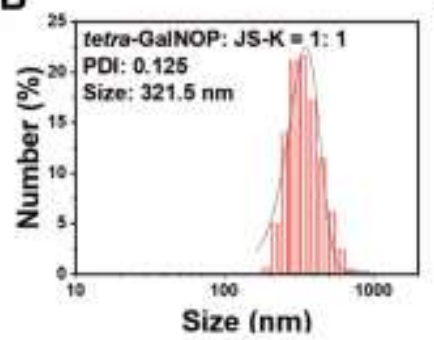

C

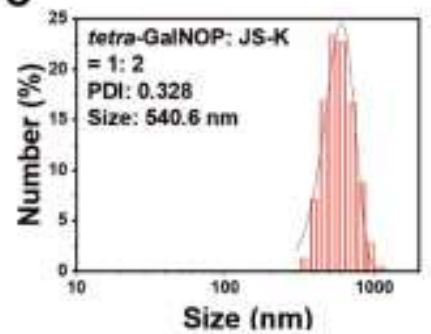

Figure S22. (A-C) Size optimization of GalNONP/C by adjusting molar ratios of tetraGalNOP and JS-K, respectively. 

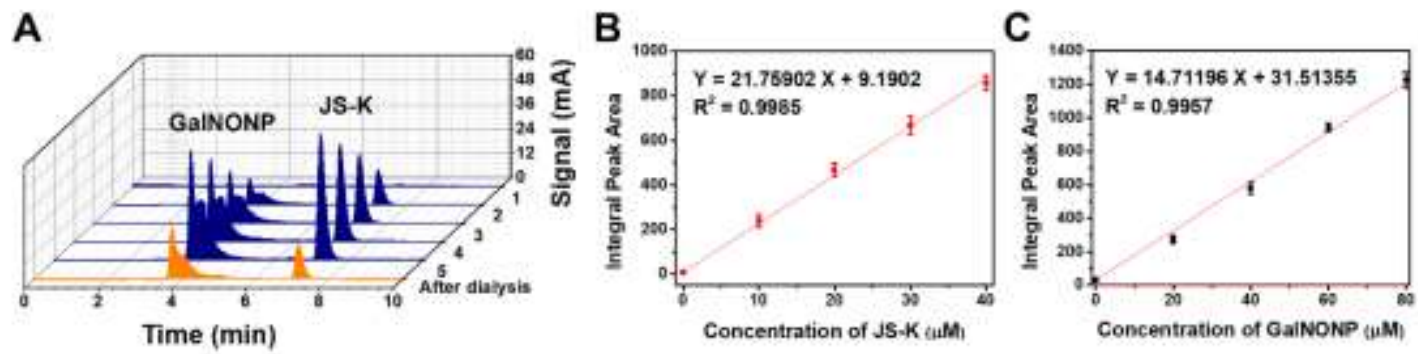

Figure S23. (A) Curves of different concentrations of GalNONP and JS-K (blue curve) and the curve of dialyzed GalNONP/C (orange curve) detected by HPLC. (B-C) The standard curves for JS-K (B) and GalNONP (C), which were obtained by taking integral peak area from (A) as Y-axis and concentration as $\mathrm{X}$-axis, respectively.

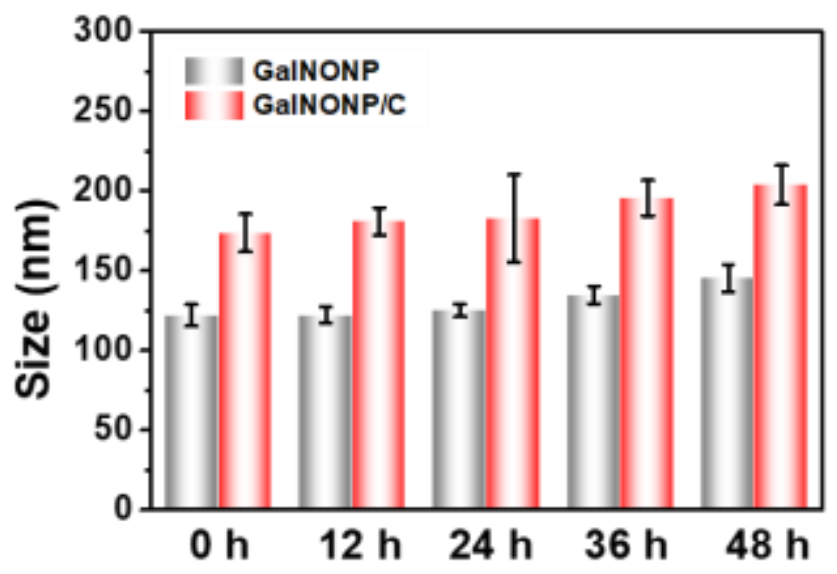

Figure S24. Micellar stability monitoring of GalNONP and GalNONP/C for 0, 12, 24, $36,48 \mathrm{~h}$ after ultrasonic self-assembly. 

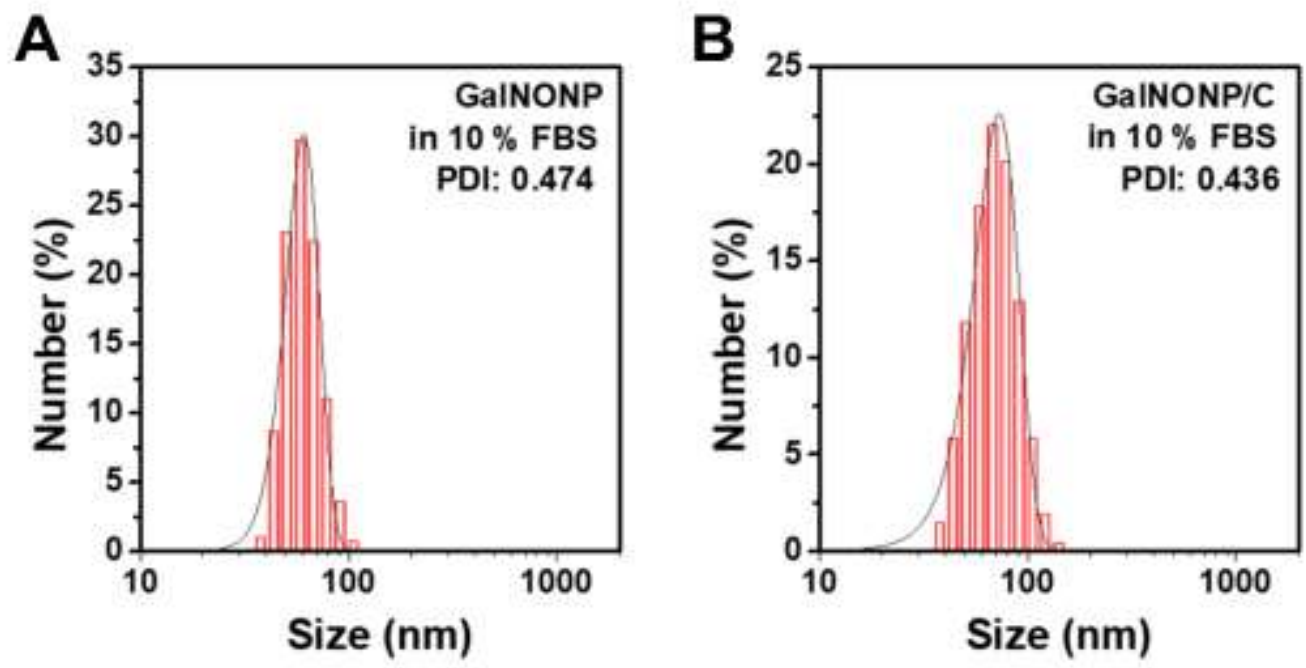

Figure S25. Micellar stability test of GalNONP (A) and GalNONP/C (B) when adding $10 \%$ FBS to corresponding micelle stock solution.

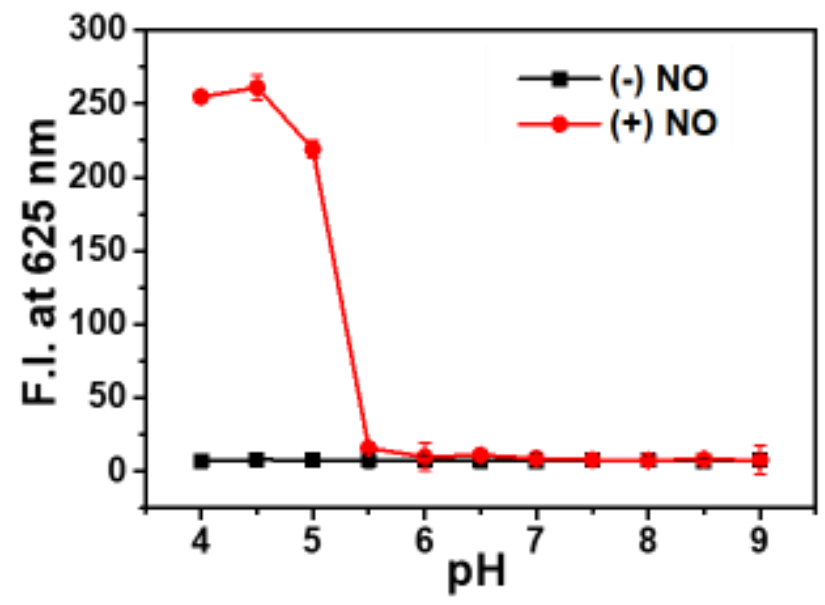

Figure S26. Fluorescence changes at $625 \mathrm{~nm}$ of $50 \mu \mathrm{M}$ GalNONP with NO (- NO) or without NO (+ NO) in different pH. Buffer: $10 \mathrm{mM} \mathrm{PB}, \lambda_{e x}=500 \mathrm{~nm}$. 


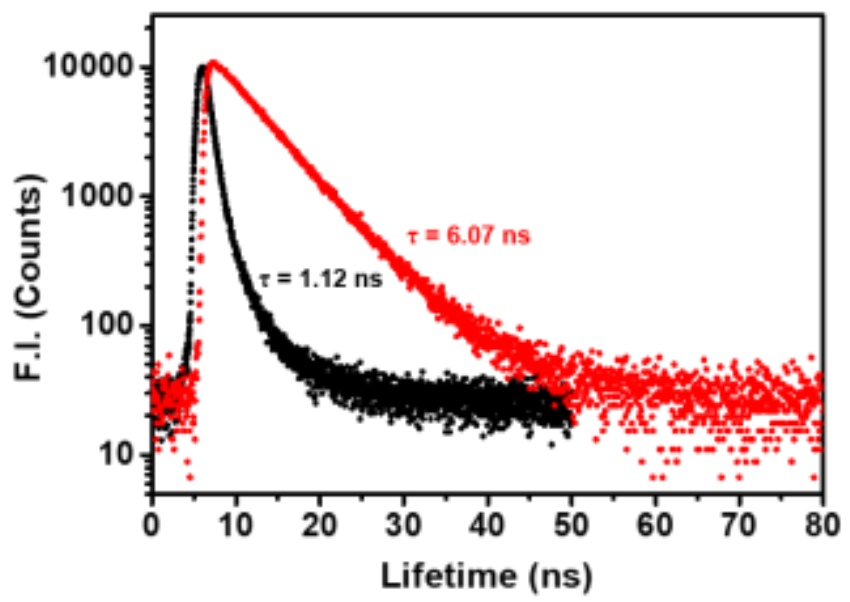

Figure S27. Fluorescence lifetime decay curves of GalNONP and NO response product.

Buffer: $10 \mathrm{mM} \mathrm{PB}, \lambda_{e x}=365 \mathrm{~nm}$ or $500 \mathrm{~nm}$. 

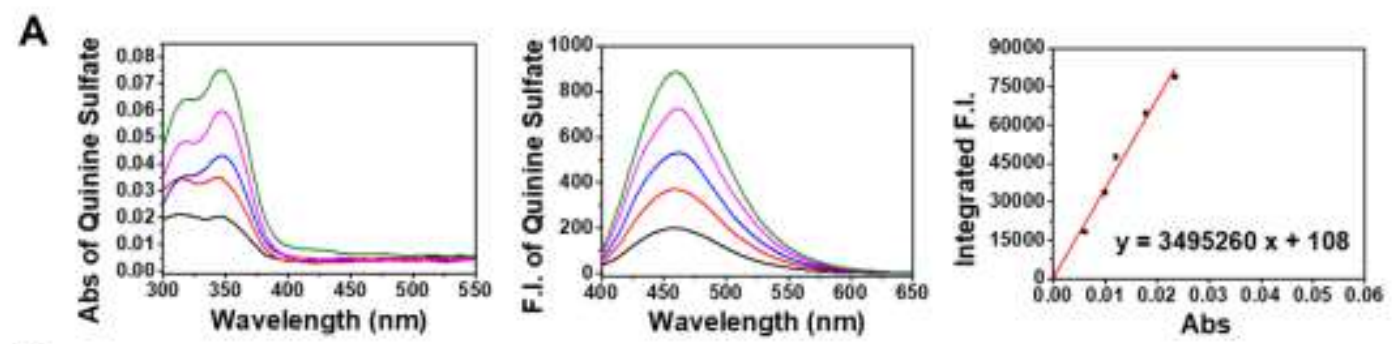

B
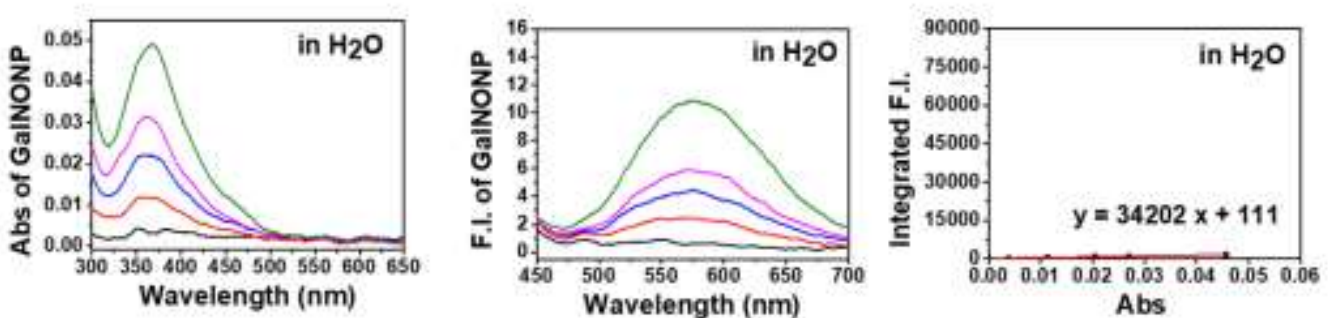

C
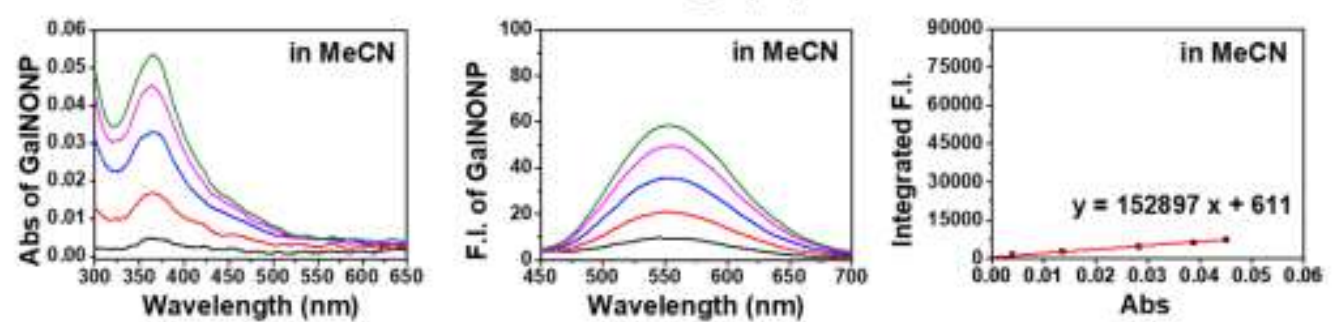

D
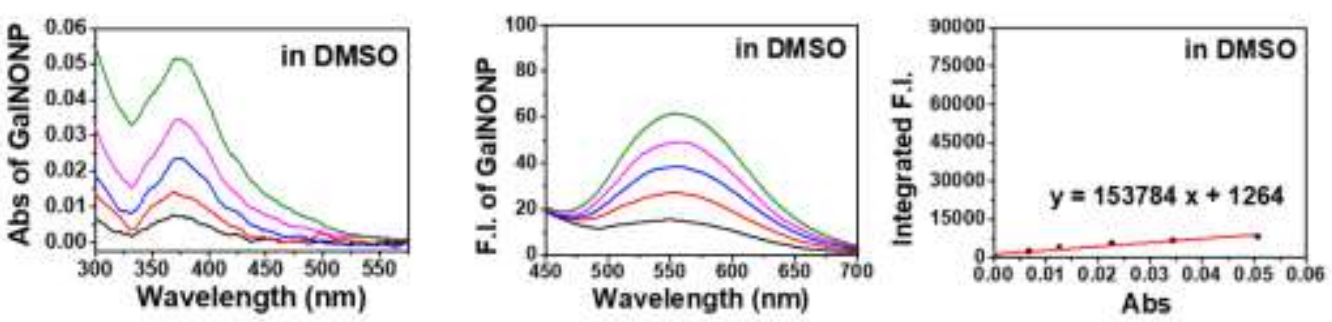

Figure S28. Measurements of fluorescence quantum yields of GalNONP. (A)

Absorption spectrums, fluorescence spectrums and the fitting line of integrated fluorescence intensities and OD values at $366 \mathrm{~nm}$ of quinine sulfate (ST) in $0.1 \mathrm{M}$ $\mathrm{H}_{2} \mathrm{SO}_{4}$. (B-D) Absorption spectrums, fluorescence spectrums and the fitting line of integrated fluorescence intensities and OD values at $366 \mathrm{~nm}$ of GalNONP in $\mathrm{H}_{2} \mathrm{O}$, $\mathrm{MeOH}$ and DMSO, respectively. $\phi_{X}=\phi_{S T}\left(\frac{\operatorname{Grad}_{x}}{\operatorname{Grad}_{S T}}\right)\left(\frac{\eta_{X}^{2}}{\eta_{S T}^{2}}\right), \eta_{S T}=1.343 ; \eta_{\text {Water }}=$ $1.340 ; \eta_{M e C N}=1.344 ; \eta_{D M S O}=1.479, \phi_{S T}=55 \% .{ }^{1} \phi_{\text {GalNONP } \text { in water }}=0.5 \%$; $\phi_{\text {GalNONP in } M e C N}=2.4 \% ; \phi_{\text {GalNONP in } D M S O}=2.9 \%$. 

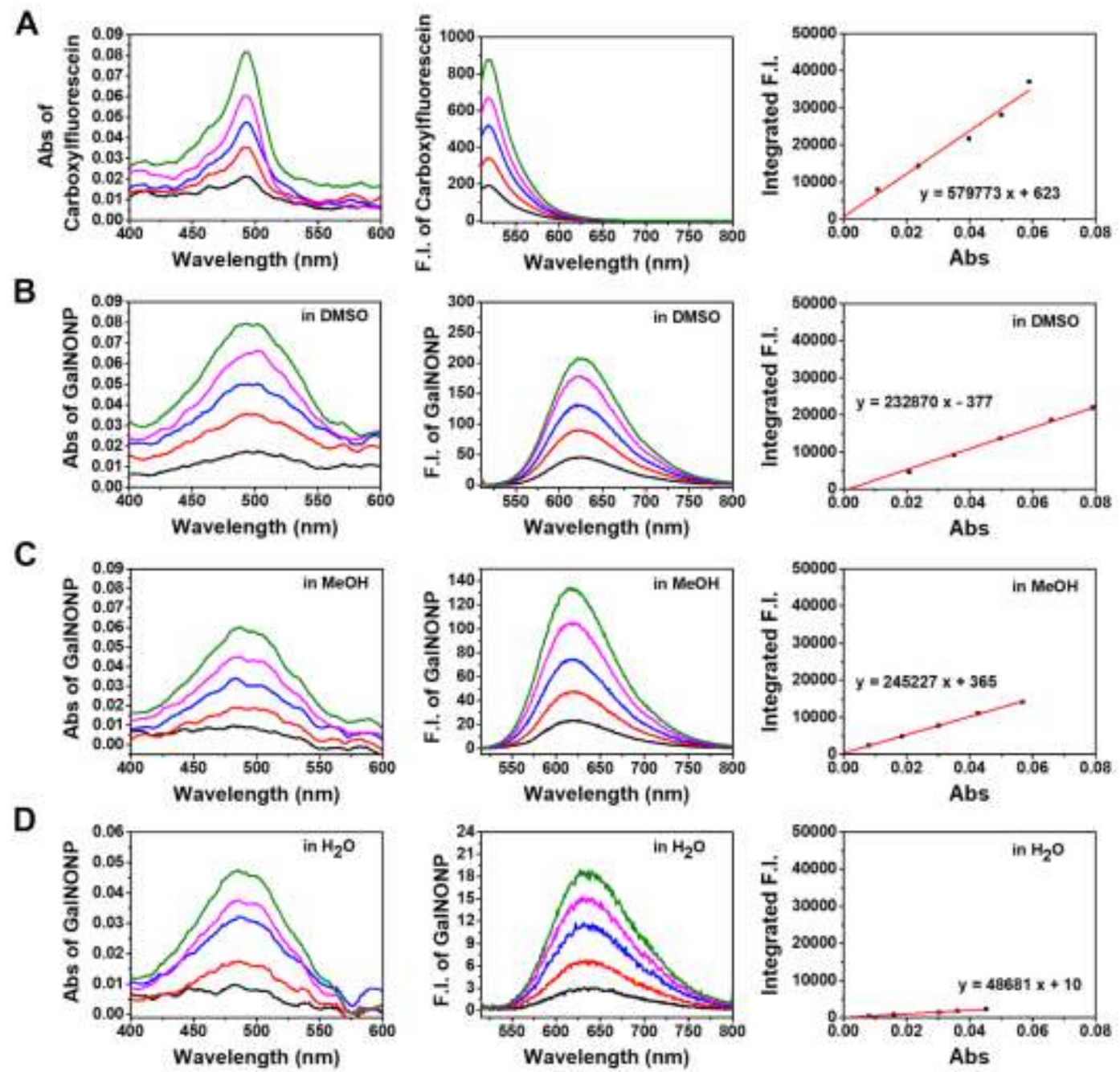

Figure S29. Measurements of fluorescence quantum yields of NO response product, GalNONP+NO. (A) Absorption spectrums, fluorescence spectrums and the fitting line of integrated fluorescence intensities and OD values at $500 \mathrm{~nm}$ of carboxylfluorescein (ST) in PBS (pH=7.4). (B-D) Absorption spectrums, fluorescence spectrums and the fitting line of integrated fluorescence intensities and OD values at $500 \mathrm{~nm}$ of GalNONP+NO in $\mathrm{H}_{2} \mathrm{O}, \mathrm{MeOH}$ and DMSO, respectively. $\phi_{X}=\phi_{S T}\left(\frac{\operatorname{Grad}_{x}}{\operatorname{Grad}_{S T}}\right)\left(\frac{\eta_{X}^{2}}{\eta_{S T}^{2}}\right)$, $\eta_{S T}=1.330 ; \eta_{\text {Water }}=1.340 ; \eta_{M e O H}=1.329 ; \eta_{D M S O}=1.479, \Phi_{S T}=83 \%{ }^{2}$ $\phi_{\text {GalNONP+NO in water }}=7.1 \% ; \quad \phi_{\text {GalNONP+NO in } \mathrm{MeOH}}=35.1 \%$; $\phi_{\text {GalNONP+NO in DMSO }}=41.2 \%$. 


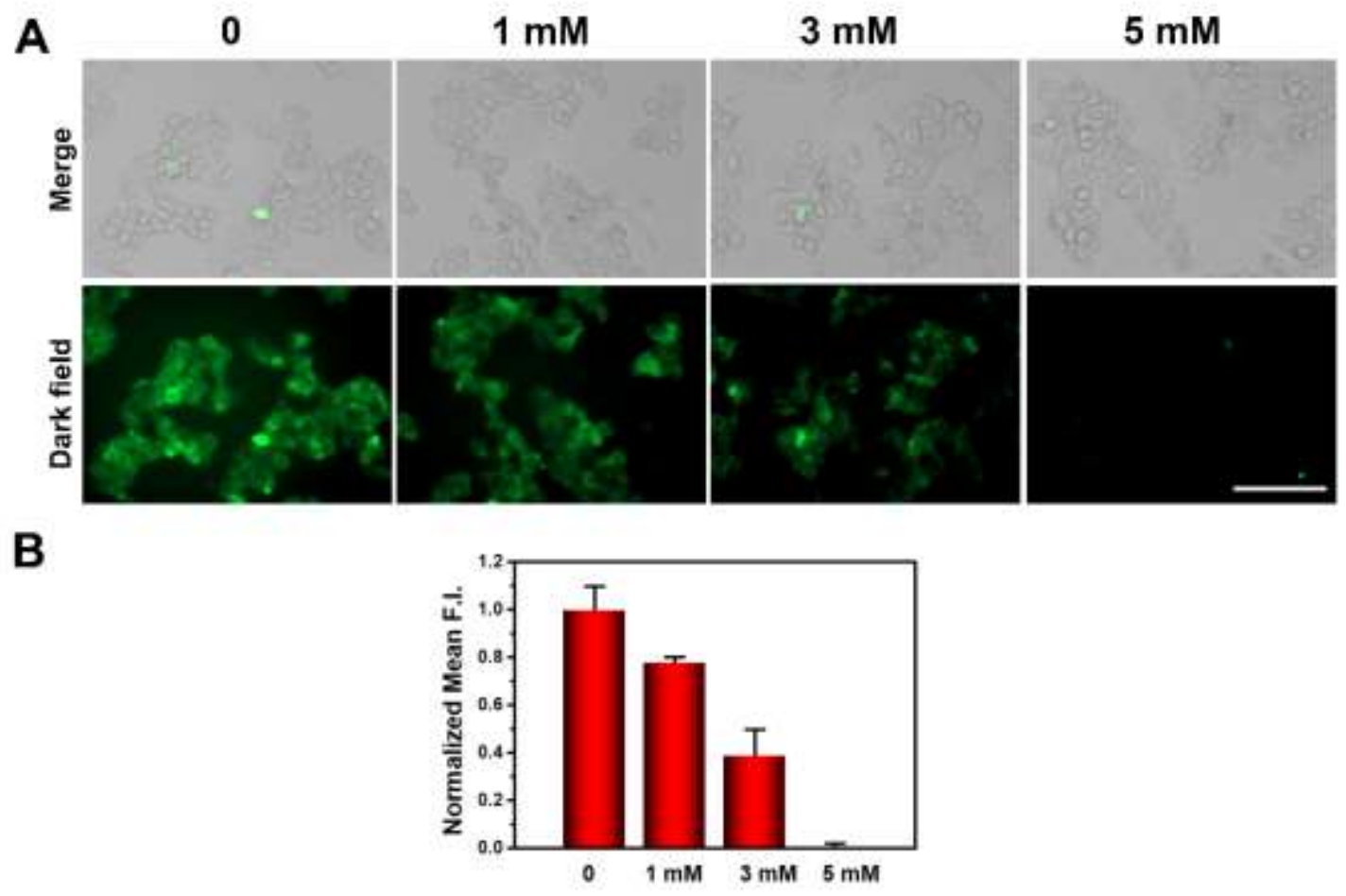

Figure S30. (A) Fluorescence images of HepG2 cells by preincubating galactose to inhibit ASGPR-mediated endocytosis of $50 \mu \mathrm{M}$ GalNONP $\left(\lambda_{e x}=469 \mathrm{~nm} ; \lambda_{e m}=525 \mathrm{~nm}\right.$; scale bars $=100 \mu \mathrm{m})$. (B) Normalized mean fluorescence intensities of (A).

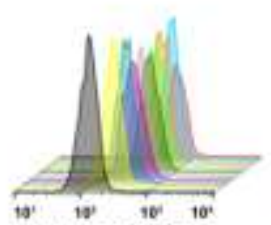

F. I. of Hela

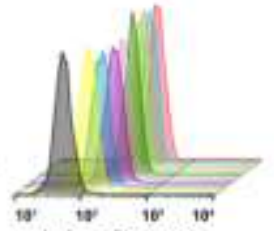

F. I. of L929

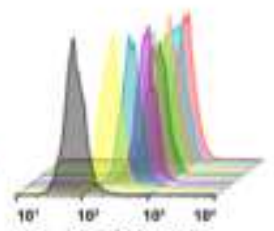

F. I. of A549

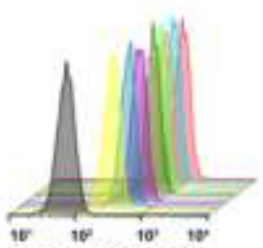

F. I. of CT26

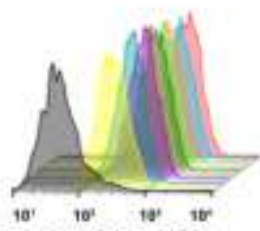

F. I. of HepG2

Figure S31. Flow cytometric examination of the cellular uptake of different cells after treating with $50 \mu \mathrm{M}$ GalNONP after $0,5,10,20,30,40,50,60,120,180$ min incubation (Green B channel: $\lambda_{e x}=488 \mathrm{~nm} ; \lambda_{e m}=525 \mathrm{~nm}$ ). 

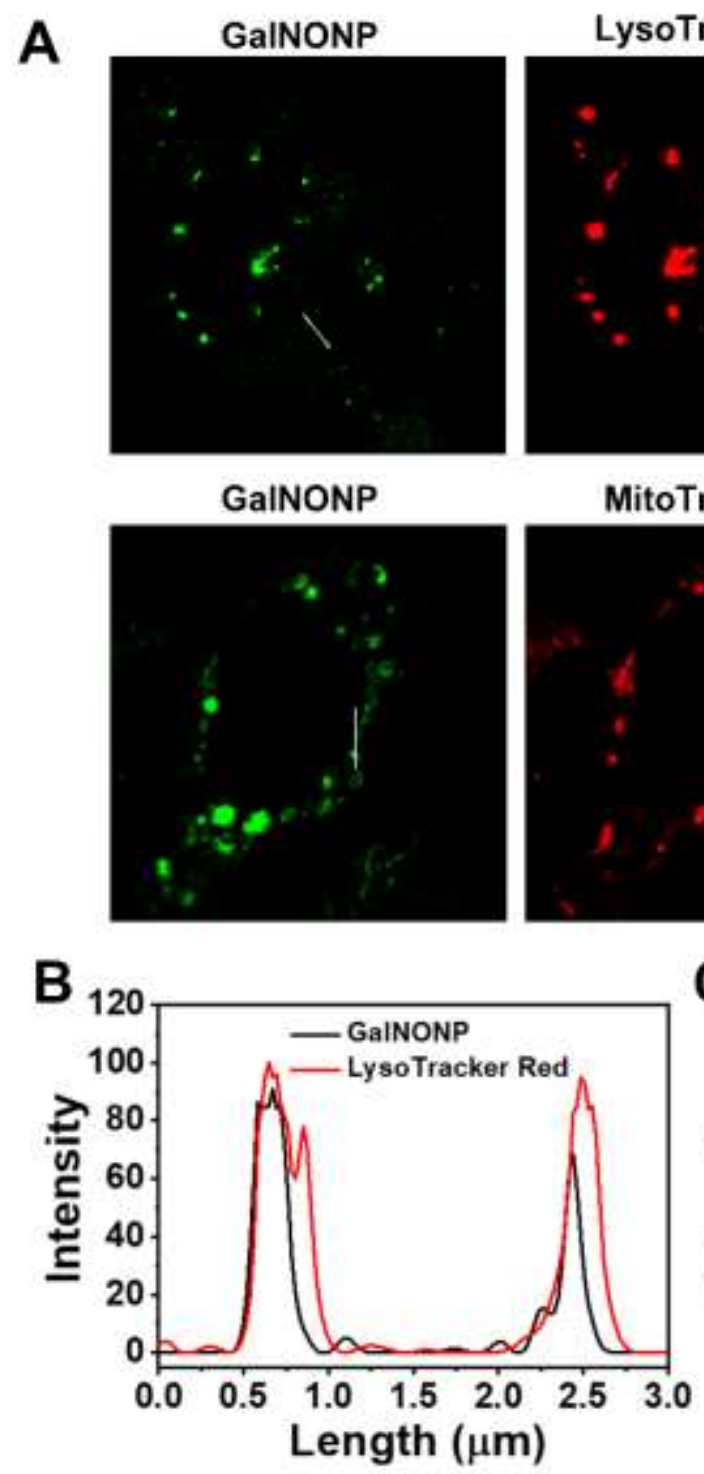

LysoTracker Red

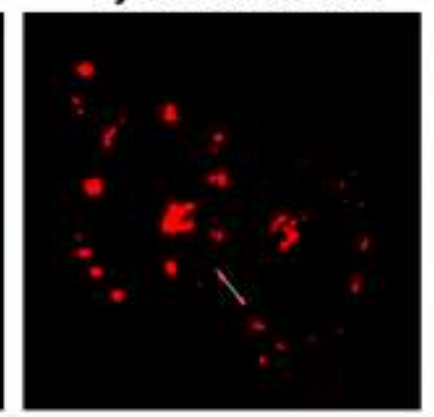

MitoTracker Red

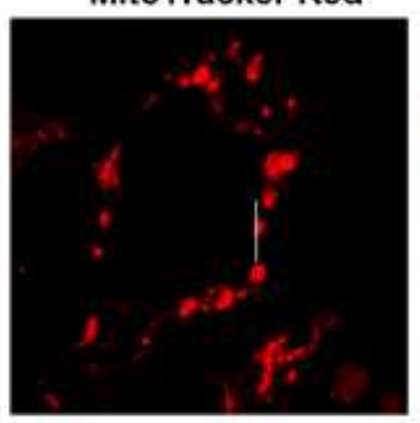

c

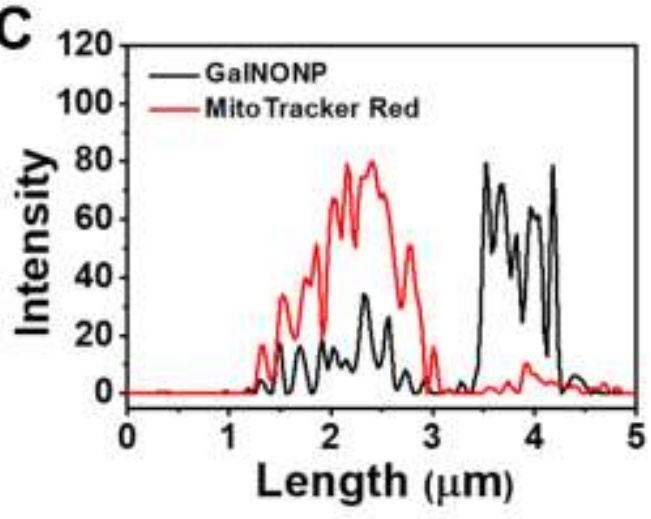

Figure S32. (A) CLSM images showing green fluorescence from GalNONP and red fluorescence from LysoTracker Red (or MitoTracker Red) in HepG2 cells. GalNONP and LysoTracker Red (or MitoTracker Red) signals were collected at 500-590 nm and 650-750 nm excited by $405 \mathrm{~nm}$ and $520 \mathrm{~nm}$ lasers, respectively. Scale bar: $15 \mu \mathrm{m})$. (B) (C) Fluorescence intensity variations along the marked lines in (A). 


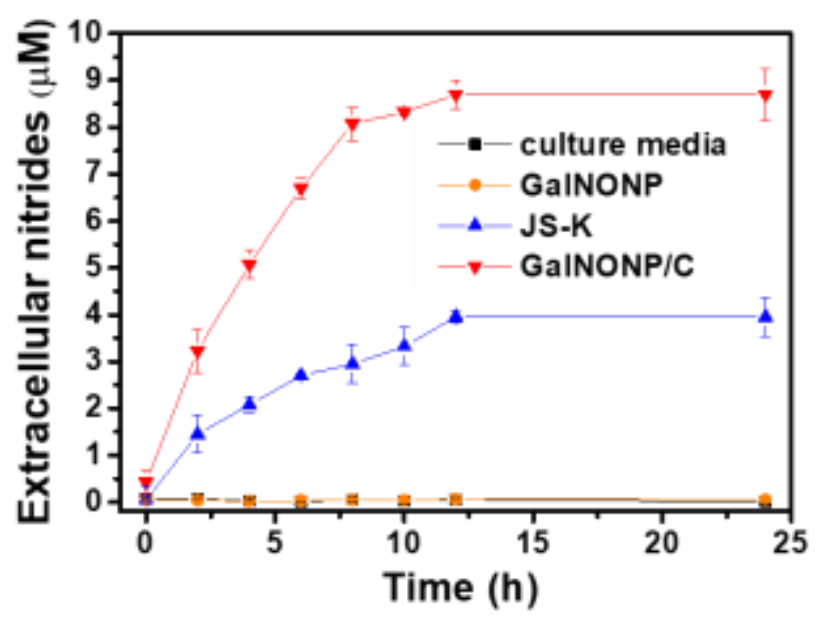

Figure S33. Extracellular nitrides from culture media, GalNONP, JS-K and GalNONP/C in HepG2 cells as determined by Griess assay at $540 \mathrm{~nm}$.
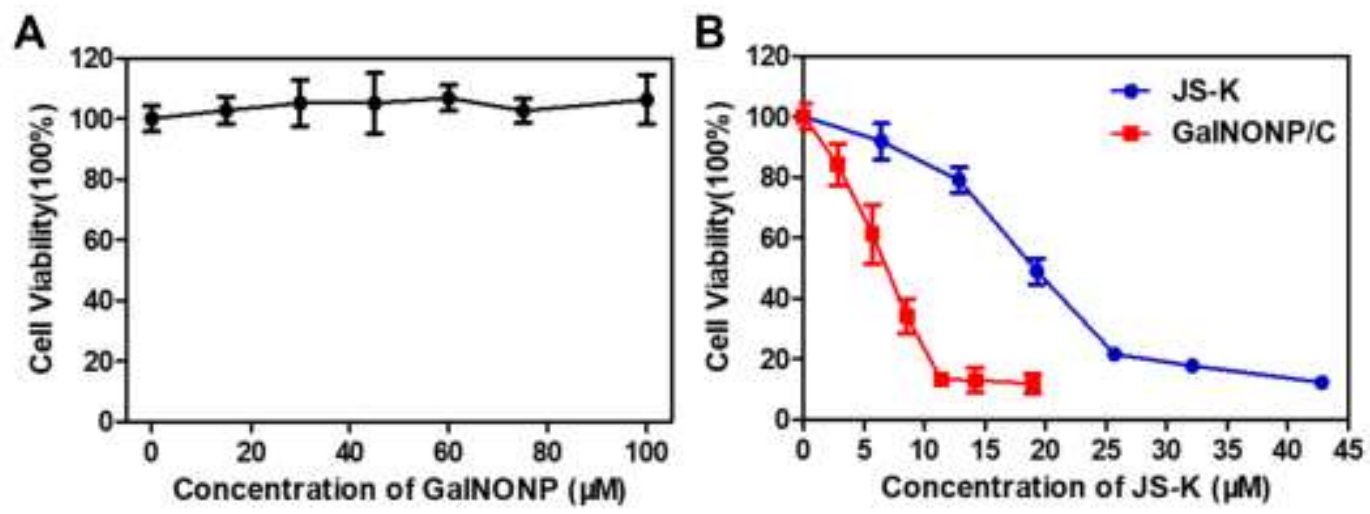

Figure S34. Cytotoxicity assay of GalNONP (A), JS-K and GalNONP/C (B) in HepG2 cells examined after $24 \mathrm{~h}$ incubation. 


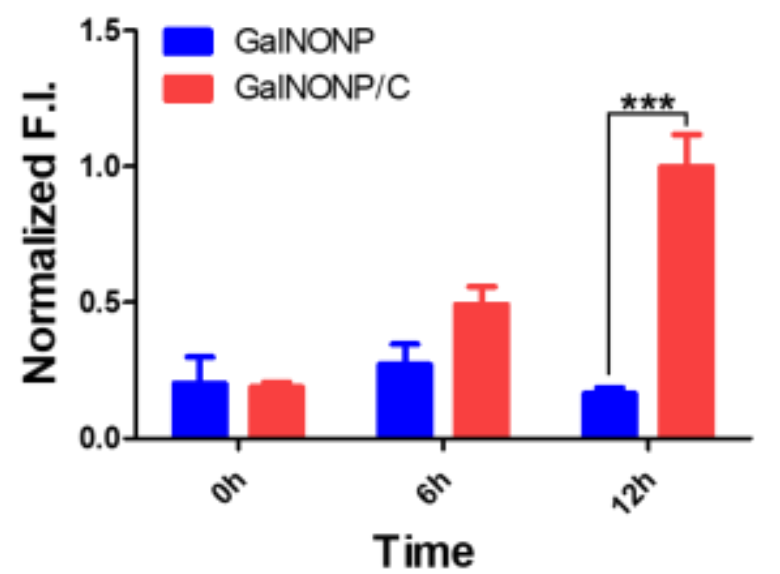

Figure S35. Normalized mean fluorescence intensities of Figure 4A. Student's $t$-test: $* * * p<0.005$
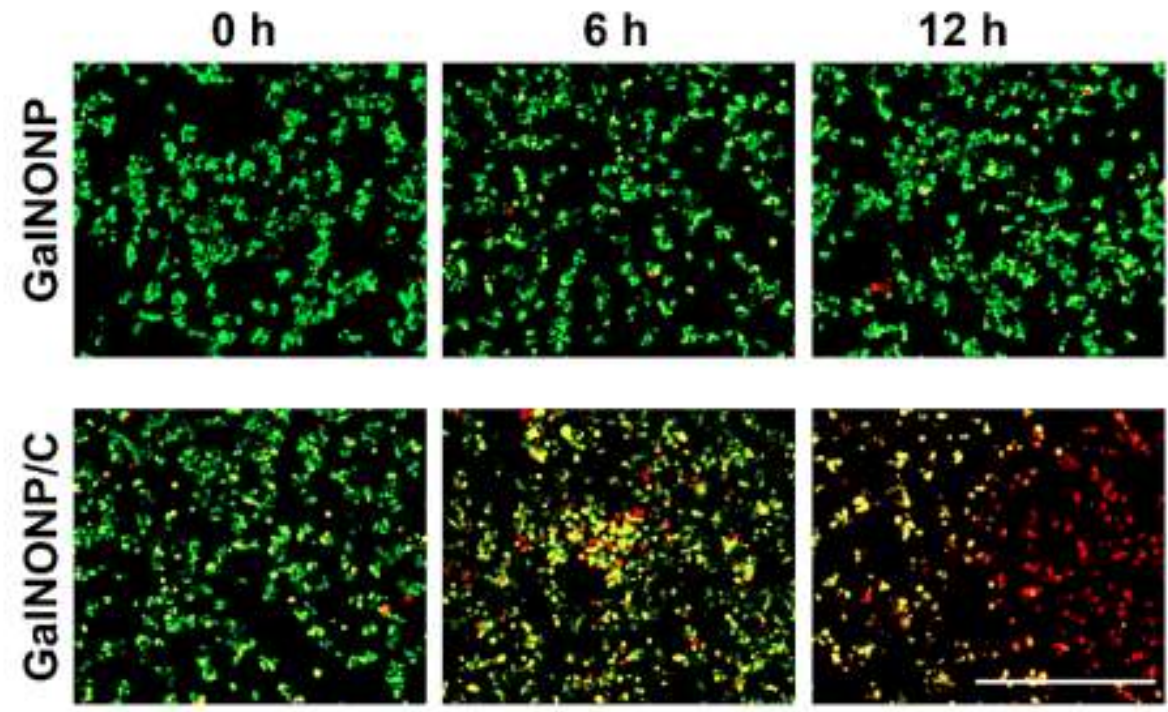

Figure S36. Live-dead staining of HepG2 cells examined at 0,6 and $12 \mathrm{~h}$ post $1 \mathrm{~h}$ incubation with $50 \mu \mathrm{M}$ GalNONP or GalNONP/C. Scale bar $=500 \mu \mathrm{m}$. 


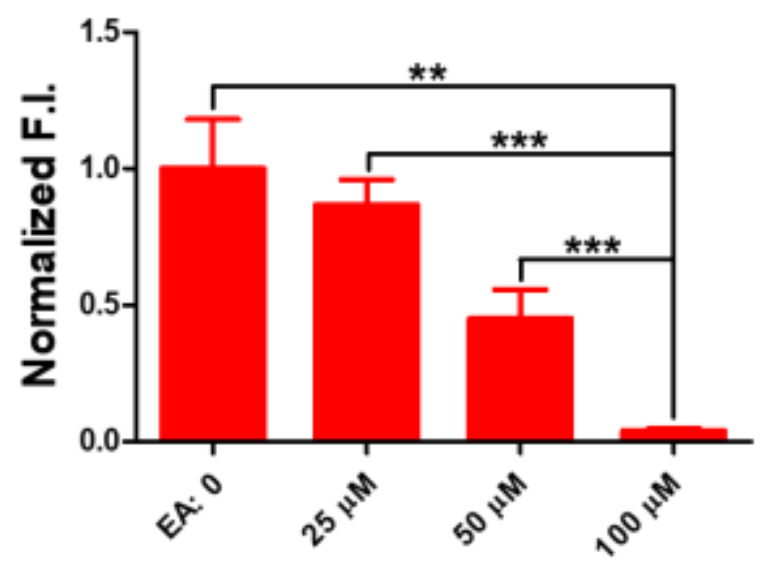

Figure S37. Normalized mean fluorescence intensities of Figure 4C. Student's $t$-test:

$* * p<0.01, * * * p<0.005$

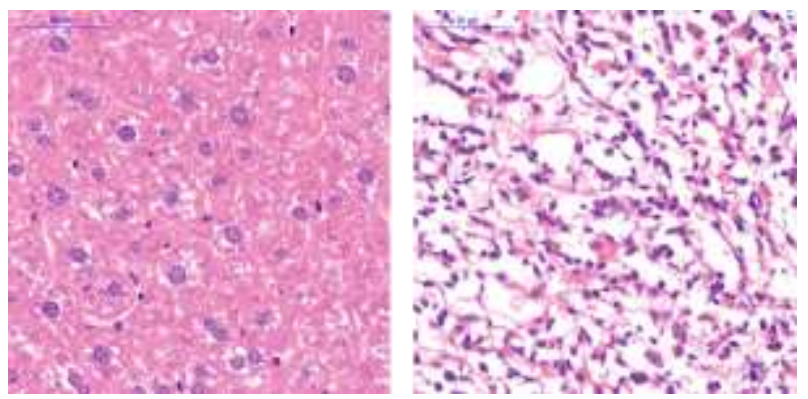

Figure S38. H\&E staining of the normal liver (left) and the tumor (right). Scale bar = $50 \mu \mathrm{m}$. 


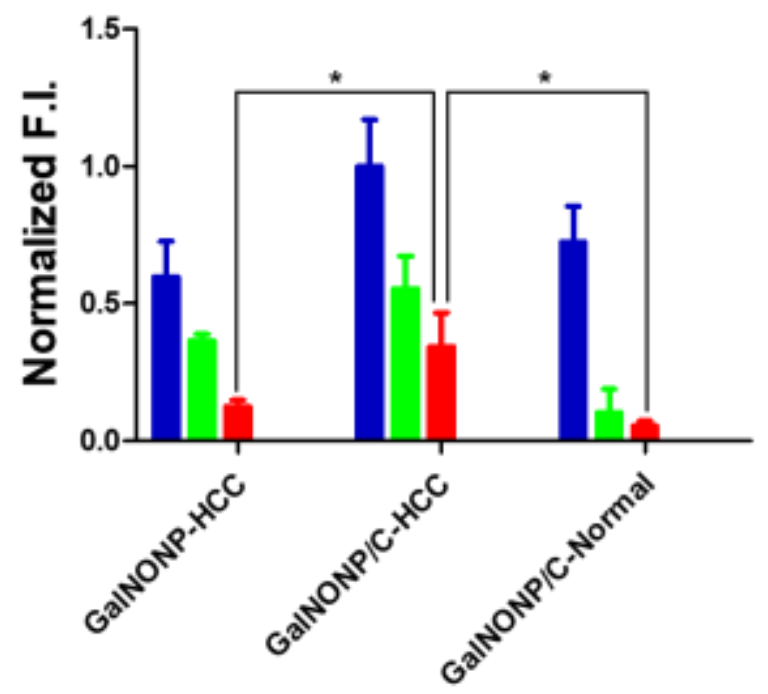

Figure S39. Normalized mean fluorescence intensities of Figure 5D. Student's $t$-test: ${ }^{*} p<0.05$.

\section{References:}

[1] Wang, D. J.; Kang, Y. F.; Fan, L.; Hu, Y. J.; Zheng, J. Synthesis and Photoluminescence Behavior of Difluoroboron Complexes with $\beta$-diketone Ligands. Opt. Mater. 2013, 36, 357-361.

[2] Povedailo, V. A.; Lysenko, I. L.; Tikhomirov, S. A.; Yakovlev, D. L.; Tsybulsky, D. A.; Kruhlik, A. S.; Fan, F.; Martynenko-Makaev, Y. V.; Sharko, O. L.; Duong, P. V.; Minh, P. H.; Shmanai, V. V. Fluorescent Properties of Carboxyfluorescein Bifluorophores. J Fluoresc, 2020, 30, 629-635. 